DANNY DE SOUZA LOPES

PROPOSTA DE PARTICIPAÇÃO DO ESTADO DO AMAZONAS EM PROJETOS DE DESENVOLVIMENTO GLOBAL DE SOFTWARE

Dissertação apresentada à Escola Politécnica da Universidade de São Paulo para obtenção do título de Mestre em Engenharia Elétrica.

São Paulo

2010 
DANNY DE SOUZA LOPES

\title{
PROPOSTA DE PARTICIPAÇÃO DO ESTADO DO AMAZONAS EM PROJETOS DE DESENVOLVIMENTO GLOBAL DE SOFTWARE
}

\author{
Dissertação apresentada à Escola Politécnica da \\ Universidade de São Paulo para obtenção do título \\ de Mestre em Engenharia Elétrica. \\ Área de Concentração: \\ Sistemas Digitais \\ Orientador: \\ Prof. Dr. Edison Spina
}

São Paulo

2010 
Este exemplar foi revisado e alterado em relação à versão original, sob responsabilidade única do autor e com a anuência de seu orientador.

São Paulo, de setembro de 2010.

Assinatura do autor

Assinatura do orientador

\section{FICHA CATALOGRÁFICA}

Lopes, Danny de Souza

Proposta de participação do Estado do Amazonas em projetos de desenvolvimento global de software / D.S. Lopes. -ed.rev. -- São Paulo, 2010.

$77 \mathrm{p}$.

Dissertação (Mestrado) - Escola Politécnica da Universidade de São Paulo. Departamento de Engenharia de Computação e Sistemas Digitais.

1. Desenvolvimento distribuído de software 2. Engenharia de requisitos 3. Sustentabilidade - Amazonas I. Universidade de São Paulo. Escola Politécnica. Departamento de Engenharia de Computação e Sistemas Digitais II. t. 


\section{DEDICATÓRIA}

À minha família, pelo amor incondicional demonstrado ao longo dessa jornada, tornando possível a conclusão desse trabalho. 


\section{AGRADECIMENTOS}

Inicialmente, meu agradecimento é para Deus, que todos os dias prova Seu amor por mim, e nesta jornada não foi diferente, pois me deu oportunidade de vivenciar experiências que só a Sua mão poderia proporcionar.

Ao prof. Dr. Edison Spina, por ter confiado desde o início neste projeto, pela motivação e apoio demonstrados durante a realização deste trabalho, além da oportunidade que tive de conviver com uma pessoa tão competente e dedicada.

À minha esposa linda, Luciana Lopes, paciente e compreensiva em muitos momentos difíceis, e aos meus dois amores, meus filhos Paulinho e Débora, presentes preciosos de Deus na minha vida.

Ao meu pai Luiz Otaviano, guerreiro e vencedor, que demonstra diariamente como ser um homem de caráter exemplar e a quem agradeço por ser o que o hoje me tornei. À minha mãe Rosemary Lopes, o maior exemplo de mulher que pude vivenciar até hoje, companheira, paciente e de uma sabedoria incomparável.

Às minhas irmãs Andreza e Alexandra, aos cunhados, amigos do trabalho que apoiaram minha pesquisa, amigos do MINTER, que estiveram lado a lado comigo na convivência diária longe de casa, mas sempre motivando e incentivando, companheiros para combate.

À FUCAPI, empresa de pesquisa sediada em Manaus, que permitiu que eu pudesse realizar o mestrado, e à SUFRAMA, pelo patrocínio financeiro ao MINTER.

À FAPEAM, pelas bolsas para o cumprimento do estágio obrigatório através do programa RH-INTERINSTITUCIONAL, e à CAPES, pela criação e regulamentação do MINTER. À UEA, por gerar condições e propiciar o oferecimento do programa de pós-graduação da EPUSP em Manaus. 


\section{RESUMO}

O Estado do Amazonas tem realizado investimentos em educação através da oferta de ensino superior em tecnologia para seus municípios, como alternativa para fomentar o desenvolvimento regional. Porém, de forma complementar, é necessário promover condições para que essas comunidades possam ter acesso a um mercado de trabalho e colocar em prática o conhecimento adquirido, sem que para isso necessitem migrar para outros centros mais desenvolvidos. Este trabalho de pesquisa apresenta uma proposta de inclusão do estado do Amazonas como agente colaborador em projetos de desenvolvimento global de software, através da criação de um conjunto de recomendações para guiar empreendedores no investimento desta solução. O método inclui a coleta de informações sobre as características particulares dos municípios do Estado do Amazonas utilizando técnicas de elicitação de requisitos com foco em engenharia de sistemas, e o estabelecimento de relação entre os problemas regionais e os principais problemas enfrentados por equipes que atuam com desenvolvimento global de software. A partir dessa relação, são geradas recomendações voltadas para capacitação de recursos humanos, investimentos em infraestrutura tecnológica e física local, oferecendo assim uma fonte alternativa de sustentabilidade ao desenvolvimento econômico da região amazônica.

Palavras-chave: desenvolvimento distribuído de software, engenharia de requisitos, sustentabilidade - Amazonas. 


\section{ABSTRACT}

Amazonas State has invested in education by offering higher education in technology for its cities, as an alternative to foster regional development. However, it is necessary to promote conditions for these communities to have access to a labor market and put into practice the acquired knowledge, without the need to migrate to other more developed cities. This work presents a proposal to inclusion of State of Amazonas as a collaborator agent in global software development projects, by establishing a set of recommendations to guide entrepreneurs in the investment of this solution. The method includes collecting information about the particular characteristics of Amazonas cities using requirements elicitation techniques with focus on systems engineering, and the establishment of relationship between the regional problems and the main issues faced by teams working with global software development. From this relationship, the recommendations are generated focused on human resources training, investments in the local physical and technological infrastructure, thus providing an alternative source of sustainability to economic development of Amazonas.

keywords: distributed software development, requirements engineering, sustainability - Amazonas. 


\section{LISTA DE FIGURAS}

Figura 1 - Método para execução deste trabalho de pesquisa...........................17

Figura 2 - Método para elaboração das recomendações .................................... 18

Figura 3 - Evolução do mercado global de serviços de TI, adaptado de Gil (2009)

Figura 4 - Ranking dos melhores destinos em outsourcing de TI e suporte.

Fonte: A.T. KEARNEY (2009)

Figura 5 - Modelos de negócios em DGS, adaptado de Audy e Prikladnicki

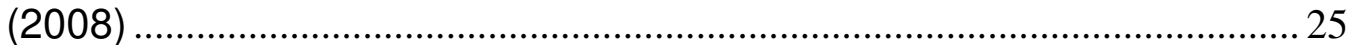

Figura 6 - Mercado mundial de TI em 2007. Fonte: IDC (2008),.................... 28

Figura 7 - Desenvolvimento follow-the-sun, adaptado de Carmel (2009).......31

Figura 8 - Categorias de desafios do DGS ....................................................... 32

Figura 9 - Modelo em espiral para o processo de engenharia de requisitos.

Fonte: Kotonya e Sommerville (1998) .......................................................... 45

Figura 10 - Representação simplificada da metodologia SSM ...........................50

Figura 11 - Representação do RSM de D. Hitchins...........................................52

Figura 12 - Mapa mental da sessão de brainstorming ........................................60

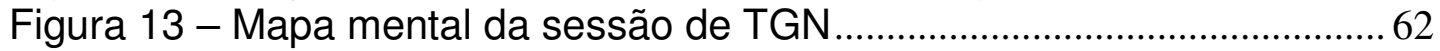

Figura 14 - A proposta sob uma visão empreendedora.........................................63

Figura 15 - Relação entre desafios do DGS e problemas regionais..................66 


\section{LISTA DE ABREVIATURAS}

\begin{tabular}{ll} 
BRASSCOM & $\begin{array}{l}\text { Associação Brasileira de Empresas de Tecnologia da } \\
\text { Informação e Comunicação }\end{array}$ \\
BPMN & Business Process Modeling Notation \\
BPO & Business Process Outsourcing \\
CETAM & Centro de Educação Tecnológica do Amazonas \\
DGS & Desenvolvimento Global de Software \\
GSLI & Global Services Location Index \\
IEEE & Institute of Electrical and Eletronic Engineers \\
ISM & Interpretive Structural Modeling \\
NASSCOM & National Association of Software and Services \\
RSM & Companies \\
SEDUC & Rigorous Soft Method \\
SPMRT & Secretaria de Estado da Educação e Qualidade do \\
SSM & Ensino \\
TADS & Sistema Presencial Mediado por Recursos Tecnológicos \\
TGN & Soft Systems Methodology \\
TI & Tecnologia em Análise e Desenvolvimento de Sistemas \\
UEA & Técnica de Grupo Nominal \\
UFAM & Tecnologia da Informação \\
& Universidade do Estado do Amazonas \\
\hline
\end{tabular}




\section{SUMÁRIO}

LISTA DE FIGURAS .......................................................................... VII

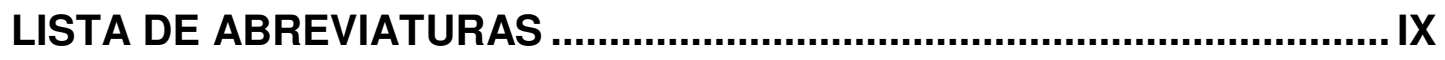

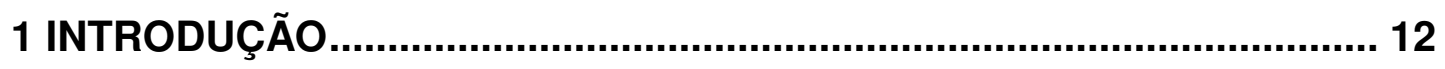

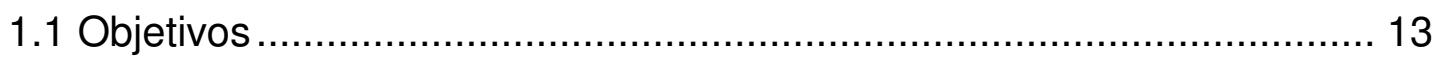

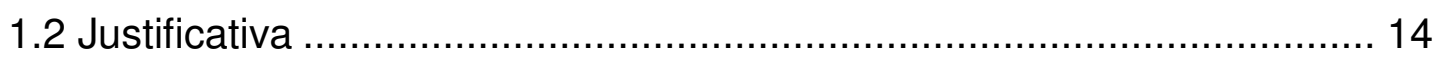

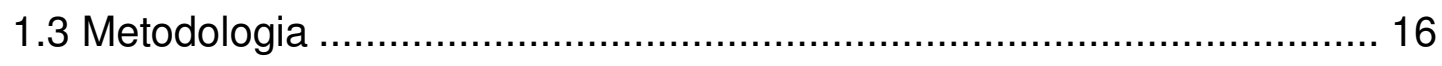

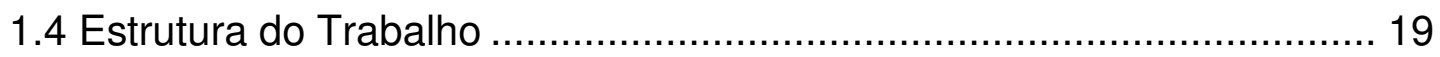

2 DESENVOLVIMENTO GLOBAL DE SOFTWARE (DGS) ........................ 20

2.1 Definição de desenvolvimento global de software ............................... 22

2.2 Modelos de negócios em desenvolvimento global de software ............. 23

2.3 Fatores motivacionais ao desenvolvimento global de software ............. 25

2.3.1 Demanda por software e mão-de-obra especializada......................... 26

2.3.2 Redução de custos de desenvolvimento ........................................ 26

2.3.3 Acesso ao mercado global............................................................ 27

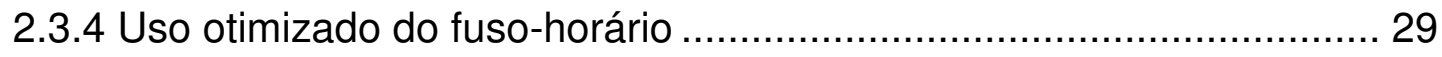

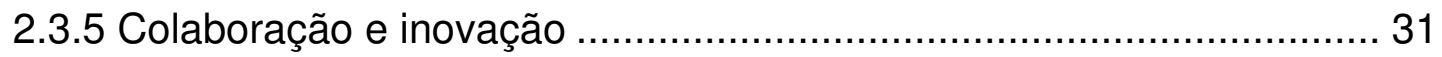

2.4 Desafios do desenvolvimento global de software ................................ 31

2.4.1 Desafios relacionados à categoria Pessoas …………………….... 33

2.4.2 Desafios relacionados à categoria Processos .................................. 35

2.4.3 Desafios relacionados à categoria Gestão....................................... 38

2.4.4 Desafios relacionados à categoria Comunicação .............................. 39

2.4.5 Desafios relacionados à categoria Tecnologia.................................. 40

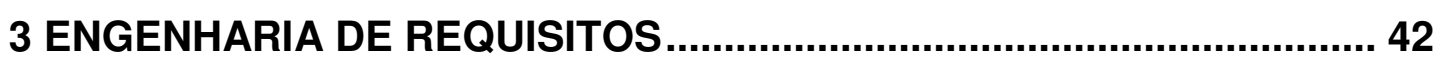

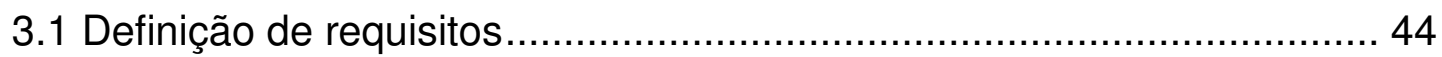

3.20 processo de engenharia de requisitos ............................................ 44

3.3 Métodos consensuais para levantamento de requisitos ....................... 46

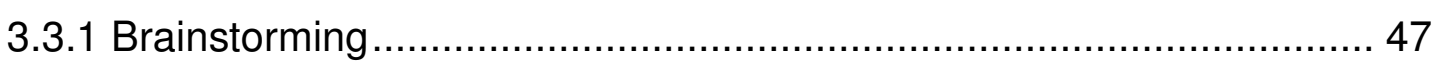


3.3.2 Técnica de Grupo Nominal (TGN) .......................................... 47

3.3.3 Escrita de Idéias ............................................................ 48

3.3.4 Modelagem Estrutural Interpretativa de Warfield .......................... 49

3.3.5 Metodologia de Sistemas Soft de Checkland............................... 50

3.3.6 Método Soft Rigoroso de Hitchins............................................... 51

4 A REALIDADE DO ESTADO DO AMAZONAS .................................. 54

4.1 Iniciativas em educação tecnológica no interior do Estado do Amazonas

4.1.1 A Universidade do Estado do Amazonas (UEA) ............................. 55

4.1.2 O Sistema Presencial Mediado por Recursos Tecnológicos (SPMRT)55

4.1.3 Curso de Tecnologia Em Análise e Desenvolvimento de Sistemas

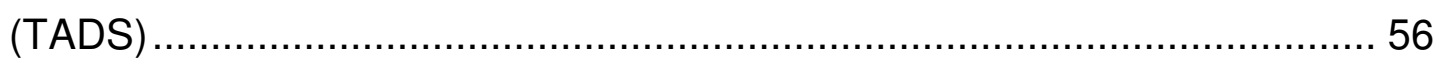

4.1.4 Secretaria de Educação do Estado do Amazonas (SEDUC-AM) ....... 57

5 PROPOSTA DE PARTICIPAÇÃO EM PROJETOS DE DESENVOLVIMENTO GLOBAL DE SOFTWARE ................................. 58

5.1 Os principais problemas regionais ............................................ 58

5.1.1 Primeira reunião: sessão de Brainstorming ................................. 59

5.1.2 Segunda reunião: sessão de Técnica de Grupo Nominal (TGN) ........ 61

5.1.3 Consolidação dos principais problemas regionais ...........................62 62

5.2 A proposta sob uma visão empreendedora ..................................... 63

5.3 As recomendações .................................................................. 65

5.3.1 Recomendações relacionadas aos recursos humanos.....................66 66

5.3.2 Recomendações relacionadas à infraestrutura física e tecnológica ... 67

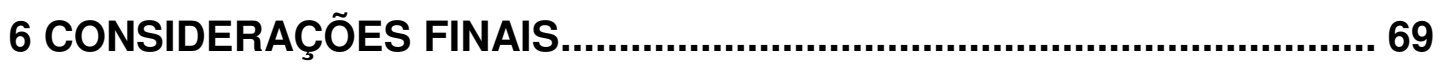

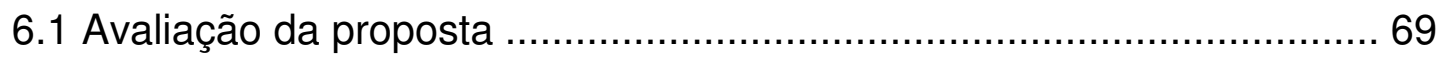

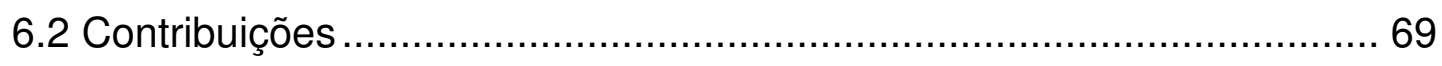

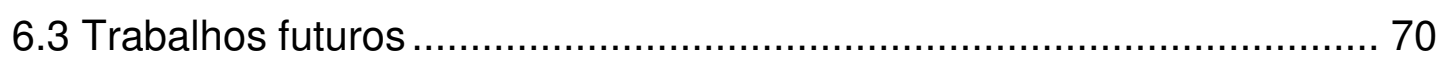

REFERÊNCIAS ................................................................................ 72 


\section{INTRODUÇÃO}

Amplamente conhecido pelas riquezas naturais que abriga, o Estado do Amazonas tem realizado diversas ações com finalidade de promover alternativas para o desenvolvimento de municípios com oportunidades reduzidas de acesso ao progresso. Isto pode ser comprovado através da busca da interiorização do crescimento econômico do estado, baseada nas potencialidades regionais, com a conseqüente geração de emprego e renda, sem ignorar o modelo industrial, já consolidado, presente na capital Manaus através de sua Zona Franca.

Todavia, o crescimento do Estado do Amazonas não deve desconsiderar as mudanças que estão alterando a forma como os países do mundo se relacionam. Este crescimento deve acompanhar estas mudanças que o mundo vem sofrendo nas últimas décadas devido aos processos de globalização.

Além de gerar mudanças nas relações econômicas, sociais, políticas e culturais entre os países, a globalização também tem impacto sobre os processos produtivos da indústria, uma vez que interfere na maneira como produtos são projetados, construídos, testados e entregues aos clientes (HERBSLEB; MOITRA, 2001).

Graças à rápida globalização das empresas, o desenvolvimento de software também teve de se adaptar a esta realidade. Em tempos onde as corporações estão se tornando cada vez mais distribuídas e cooperando mutuamente por todo o mundo, o desenvolvimento de software em projetos internacionalmente distribuídos, onde o software é desenvolvido em várias localidades geograficamente distantes, é um dos grandes desafios da atualidade.

O Desenvolvimento Global de Software (DGS) ocorre quando duas ou mais equipes estão separadas por fronteiras nacionais e atuam de forma colaborativa em projetos comuns (CARMEL, 1997), caracterizados 
fortemente pela dispersão física e temporal de seus participantes. O objetivo das empresas que adotam desenvolvimento global de software basicamente é buscar capitalização através dos diversos atrativos que este cenário proporciona: a possibilidade de atuar em novos mercados, obter vantagens decorrentes de fusões e aquisições, proximidade do cliente, minimizar custos e utilizar recursos geograficamente dispersos, além da possível redução do tempo gasto para inserção de um produto no mercado através do uso otimizado dos diferentes fusos-horários (KAROLAK, 1998), (CARMEL; DUBINSKY; ESPINOSA, 2009) e (CONCHÚIR et al., 2009).

Além dos potenciais benefícios gerados pelo DGS, há também um vasto conjunto de desafios que se apresentam ao desenvolver softwares de forma distribuída. Diversos estudos têm sido relatados nos últimos anos para mostrar soluções para as dificuldades geradas principalmente pela distância física e temporal entre os times participantes de projetos de DGS, tais como o senso de equipe e colaboração dos participantes, confiança, um idioma comum, questões relacionadas a diferenças de fuso-horário, entre muitos outros (KOMMEREN; PARVIAINEN, 2007), (MULLICK et al., 2006), (CARMEL; ARGWAL, 2001).

Ao considerar os atrativos do DGS, este se apresenta como uma excelente alternativa para sustentar o desenvolvimento econômico de diversos municípios amazonenses.

\subsection{Objetivos}

O objetivo deste trabalho é apresentar um conjunto de recomendações definidas através de uma proposta para inclusão do estado do Amazonas como participante em projetos de desenvolvimento global de software. Estas recomendações têm como objetivo prover uma série de ações para entidades que desejarem inserir municípios do Amazonas no universo do DGS e que, para isso, devem atender um conjunto de requisitos mínimos, levando em consideração os principais problemas apontados pelas experiências relatadas em trabalhos presentes na literatura sobre 0 assunto. 
Para atender ao objetivo geral deste trabalho, os seguintes objetivos específicos são apresentados:

- Identificar as características presentes nos municípios amazonenses quanto à infraestrutura física e tecnológica atual, além das potencialidades para atuar com desenvolvimento de software;

- Investigar principais desafios ao desenvolver software com equipes em escala global de distribuição geográfica e que soluções se apresentam como satisfatórias para resolvê-los;

- Identificar e avaliar requisitos mínimos de infraestrutura física, infraestrutura tecnológica, e qualificação de recursos humanos voltados para a realidade amazônica;

- Elaborar um conjunto de ações que possam prover os requisitos mínimos necessários para participação em projetos de DGS.

\subsection{Justificativa}

O Desenvolvimento Global de Software já é uma realidade para inúmeras empresas ao redor do mundo. É comum encontrar equipes de desenvolvimento de software dispersas em um país ou em vários continentes. As organizações têm distribuído geograficamente 0 desenvolvimento de software cada vez mais (DAMIAN; MOITRA, 2006).

Ao longo da última década, países como a Índia têm desenvolvido excelentes serviços de TI e softwares voltados para exportação. Atraídos pela disponibilidade de mão-de-obra qualificada, e acima de tudo pelo seu baixo custo, empresas em países com altos custos salariais, tais como Estados Unidos e Reino Unido, adotam cada vez mais o offshoring de software e serviços para países com custos salariais reduzidos (ASPRAY; MAYADAS; VARDI, 2000). 
Esta tendência é comprovada no relatório da National Association of Software and Services Companies- NASSCOM ${ }^{1}$, que afirma que a Índia absorveu uma fatia superior a $50 \%$ da indústria de offshoring de TI na última década, com crescimento dos US\$ 4 bilhões em receitas em 1998 para um total de US\$ 52 bilhões atualmente, empregando mais de 2 milhões de pessoas, e tem gerado impactos sem precedentes na economia deste país (NASSCOM, 2009).

O Global Services Location Index - GSLI, índice criado pela empresa de consultoria A.T. Kearney, analisa e classifica os 50 países do mundo como melhores destinos na prestação de atividades de outsourcing, incluindo serviços e suporte de $\mathrm{TI}$ e centrais de atendimento, utilizando métricas agrupadas em três categorias: atratividade financeira, excelência e disponibilidade de recursos humanos, e ambiente de negócios. Desde sua criação, em 2004, a Índia permanece até então em primeiro lugar e não dá sinais de que deixará de ocupar esta posição em curto prazo.

É necessário, porém, criar alternativas ao mercado indiano frente ao crescente volume de demanda de serviços de $\mathrm{Tl}$ e aos eventos recentes que externaram algumas vulnerabilidades da Índia.

O Brasil está longe de concorrer com a Índia, porém figura como importante ator no cenário mundial de outsourcing de $\mathrm{TI}$, ocupando a $12^{\circ}$ posição no ranking da GSLI, o $2^{\circ}$ da América Latina. O país carrega consigo diversos potenciais atrativos, dentre eles um ambiente de negócios altamente favorável, com sua economia ocupando a 10ำ posição do ranking mundial e a 8ํㅗำ poscão mundial em mercado de TI, mostrando importante estabilidade econômica e política.

Em busca de um melhor posicionamento econômico no contexto nacional, diversas iniciativas têm sido desencadeadas nos últimos anos com objetivo de buscar um futuro promissor para o estado do Amazonas, através de investimentos em conhecimento para formação de um mercado sustentável,

\footnotetext{
${ }^{1}$ Criada em 1988 para facilitar negócios e a comercialização de software e serviços e para encorajar o avanço nas pesquisas em tecnologia de software, a NASSCOM é a câmara de comércio da indústria de outsourcing de TI na Índia.
} 
respeitando a cultura regional, preservando o meio ambiente, gerando riquezas para os municípios e a inclusão social. Dentre algumas iniciativas, podem ser citadas a Universidade do Estado do Amazonas (UEA), o Centro de Educação Tecnológica do Amazonas (CETAM) e a Universidade Federal do Amazonas (UFAM), com projetos que levam ensino de qualidade para municípios amazonenses.

O mercado de desenvolvimento de software em escala global pode atrair investimento estrangeiro em tecnologia, infraestrutura e principalmente qualificação profissional. $O$ estado do Amazonas pode utilizar este segmento do mercado e prover uma fonte adicional para o desenvolvimento regional, através da tecnologia, oferecendo serviços de desenvolvimento de produtos de software, e despontar como um pólo preparado para interagir com um mercado cada vez mais globalizado.

\subsection{Metodologia}

Para alcançar os objetivos, será adotado um método composto pelas etapas de pesquisa bibliográfica, levantamento e avaliação de dados e elaboração das recomendações. Estas atividades estão detalhadas na figura 1, representadas através da notação BPMN² .

A primeira parte constitui a realização de pesquisa bibliográfica, através de artigos e trabalhos publicados na área de DGS com relatos acadêmicos e experiências da indústria principalmente, com o objetivo de obter conhecimento sobre a área de DGS: fundamentos, características e modelos de negócios que podem ser aplicados, identificação dos fatores levam as organizações a adotarem esta forma de desenvolvimento, além de catalogar os principais problemas e desafios enfrentados por empresas que adotam 0 DGS e como elas têm aplicado soluções para contorná-los.

\footnotetext{
${ }^{2}$ BPMN é o acrônimo de Business Process Modeling Notation, uma notação gráfica para modelar processos de negócio, mantida pela Object Management Group, Inc. - OMG, entidade sem fins lucrativos.
} 


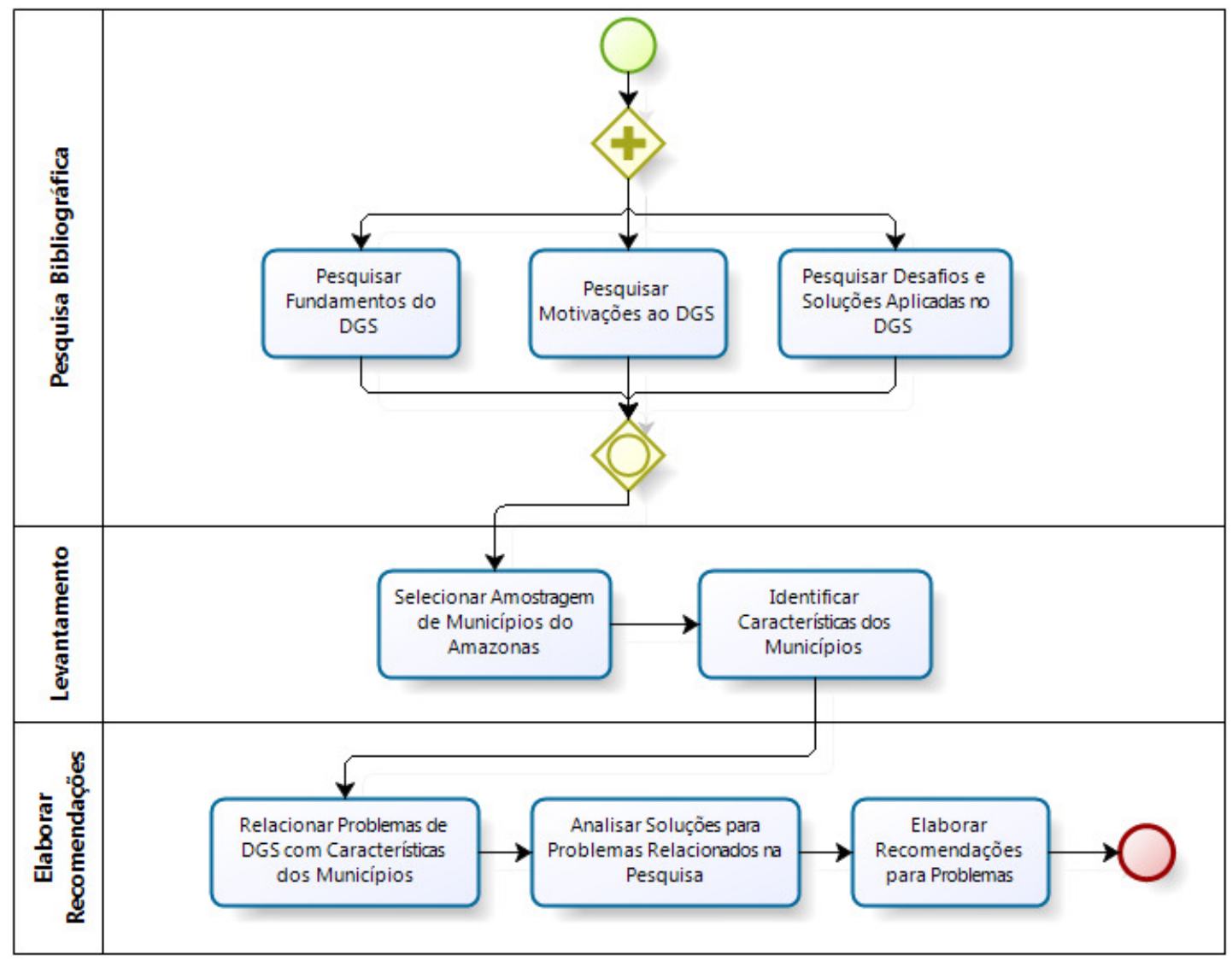

Figura 1 - Método para execução deste trabalho de pesquisa

$\mathrm{Na}$ segunda parte, o objetivo é realizar um levantamento, procedimento técnico que envolve a interrogação direta de pessoas cujo comportamento se deseja conhecer. Neste trabalho, o alvo a ser alcançado na coleta é um conjunto de atributos que determinem as características dos municípios do Amazonas, evidenciando suas peculiaridades. Neste sentido, 0 levantamento é realizado através de entrevistas junto a pessoas que estejam envolvidas em atividades nos municípios do Estado do Amazonas e que tenham conhecimento sobre a realidade dessas localidades quanto à infraestrutura e educação principalmente. Para isso são aplicados conceitos de engenharia de requisitos, especificamente sobre levantamento de requisitos, que possibilitam coletar esses dados de maneira eficaz.

De posse das características dos municípios do Amazonas, representadas através de pontos fracos que precisam ser desenvolvidos, e também do catálogo de problemas e respectivas soluções extraídos da literatura, é 
estabelecida uma relação entre eles, quando possível, de maneira a ter informações suficientes para finalmente definir recomendações para atender às necessidades que um modelo de desenvolvimento globalmente distribuído de software exige.

Para gerar o conjunto de ações recomendáveis, adota-se o método representado na figura 2 :

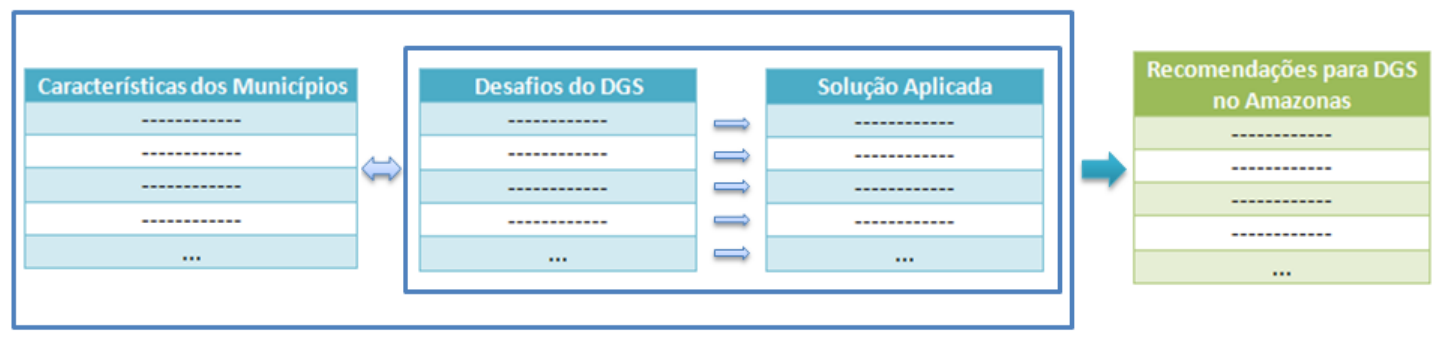

Figura 2 - Método para elaboração das recomendações

Para cada característica regional, é analisada uma possível relação com um desafio decorrente do DGS. Se identificada essa relação, a partir de então é verificada qual a solução que foi aplicada para resolver o problema, ou pelo menos mitigá-lo. Com isso, para cada subconjunto de características regionais versus desafios do DGS, são criadas recomendações voltadas para o contexto amazônico.

O objetivo é mapear a experiência local sobre a região e também a experiência mundial sobre DGS e verificar como, através da relação entre estes dois temas, é possível estabelecer uma agenda de ações para potencializar as oportunidades de ingresso no mercado de desenvolvimento globalmente distribuído de software.

A proposta busca centralizar as ações nos seguintes pilares:

- Pessoas: recomendações para qualificação de pessoal, com preparação do corpo técnico para atender a demanda de desenvolvimento distribuído de software e para lidar com os problemas que esta forma de desenvolvimento traz consigo; 
- Infraestrutura física e tecnológica: prover uma lista de itens que devem ser considerados como essenciais de forma a oferecer condições para que seja possível exercer as atividades de forma estável e contínua.

\subsection{Estrutura do Trabalho}

Este capítulo introdutório apresenta os objetivos, a justificativa e a metodologia da pesquisa. $O$ trabalho descreve a pesquisa realizada para atingir os objetivos apresentados na seção 1.1. Para isso, os próximos capítulos encontram-se organizados da seguinte forma:

- Capítulo 2: apresenta o desenvolvimento global de software, com a definição, os modelos de negócios existentes, quais os fatores motivacionais e os principais desafios do desenvolvimento global de software;

- Capítulo 3: apresenta conceitos sobre a engenharia de requisitos voltados para engenharia de sistemas e os principais métodos consensuais para levantamento de requisitos;

- Capítulo 4: descreve a realidade do Estado do Amazonas quanto aos aspectos relacionados à educação;

- Capítulo 5: descreve a proposta elaborada na pesquisa, apresentando inicialmente os principais problemas regionais e como os métodos consensuais apresentados no capítulo 3 foram aplicados na identificação desses problemas. Em seguida são apresentadas as recomendações que compõem a proposta;

- Capítulo 6: apresenta as considerações finais do trabalho, descrevendo as principais contribuições e trabalhos futuros. 


\section{DESENVOLVIMENTO GLOBAL DE SOFTWARE (DGS)}

A globalização vem transformando diversos segmentos da sociedade, eliminando fronteiras econômicas, culturais e sociais. Graças a forças econômicas, mercados locais estão se transformando em mercados globais, gerando novas formas de competição e colaboração. Esta transformação foi descrita por Herbsleb (2001), e atualmente, aproximadamente oito anos mais tarde, é possível constatar esta mudança.

Segundo relatório divulgado pela Associação Brasileira de Empresas de Tecnologia da Informação e Comunicação (BRASSCOM), em estudo encomendado à empresa de consultoria internacional A.T. Kearney, os números do mercado global em terceirização de serviços de $\mathrm{TI}$ cresceram de US $\$ 50$ bilhões em 2007 para US\$ 70 bilhões em 2008, com expectativa de expansão de $20 \%$ até 2010 , alcançando um mercado global de US\$ 101 bilhões em offshore outsourcing, como pode ser observado no gráfico da figura 3 .

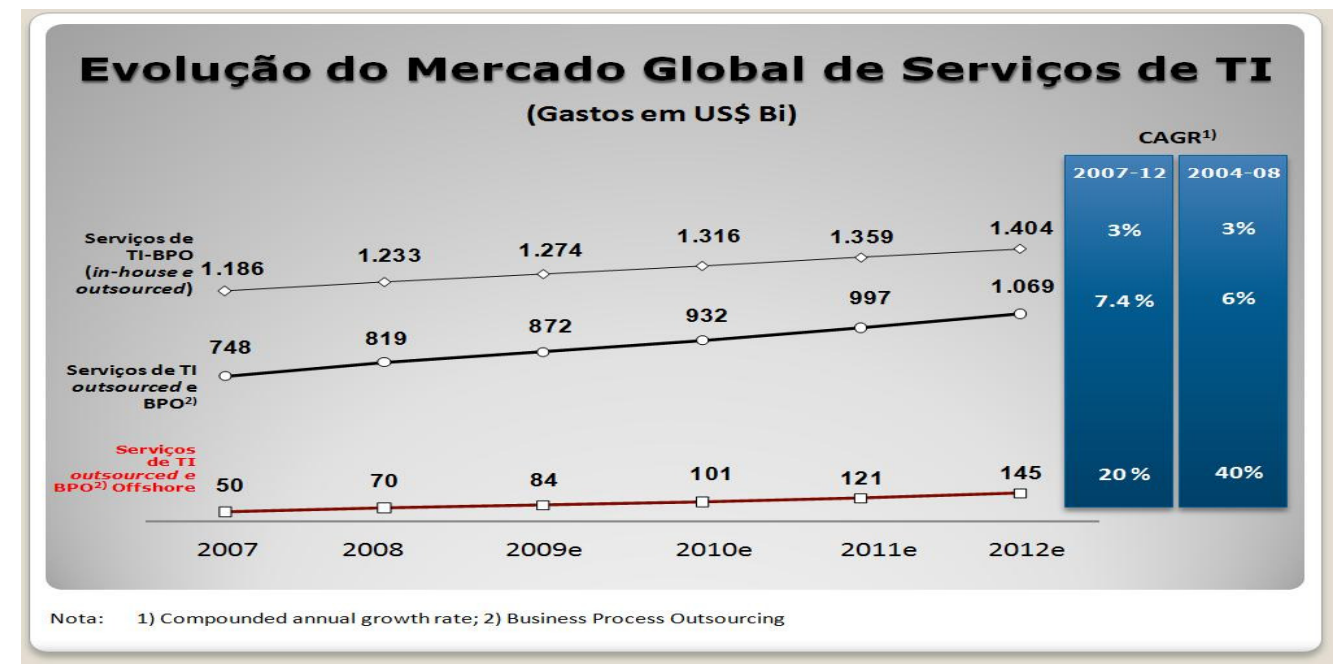

Figura 3 - Evolução do mercado global de serviços de TI, adaptado de Gil (2009)

Ao analisar o gráfico, é possível observar projeções sobre o mercado global de exportação de serviços de TI nos próximos anos: o mercado global 
crescerá a uma taxa de $3 \%$ ao ano (serviços de TI-BPO insourced e outsourced), a terceirização (serviços de TI outsourced e BPO) crescerá 6\% ao ano, enquanto o mercado de offshore destes serviços crescerá a uma taxa de expressivos $20 \%$ ao ano, em contraposição a atual crise econômica mundial.

Desde 2004 a consultoria americana A.T. Kearney publica um índice com os destinos preferidos no mercado de offshoring. A figura 4 apresenta a relação parcial com os 15 primeiros do ranking. As descobertas do ranking na edição de 2009 (A.T. KEARNEY, 2009) refletem este ambiente instável de recessão. Enquanto alguns centros consolidados de outsourcing estão enfraquecendo - nove países caíram nove ou mais posições em relação ao ranking anterior - novas estrelas ascendentes estão mudando a paisagem do mercado de outsourcing.

\begin{tabular}{|c|c|c|c|c|c|}
\hline Rank & Country & $\begin{array}{c}\text { Financial } \\
\text { attractiveness }\end{array}$ & $\begin{array}{c}\text { People skills } \\
\text { and availability }\end{array}$ & $\begin{array}{c}\text { Business } \\
\text { environment }\end{array}$ & Total score \\
\hline 1 & India & 3.13 & 2.48 & 1.30 & 6.91 \\
\hline 2 & China & 2.59 & 2.33 & 1.37 & 6.29 \\
\hline 3 & Malaysia & 2.76 & 1.24 & 1.97 & 5.98 \\
\hline 4 & Thailand & 3.05 & 1.30 & 1.41 & 5.77 \\
\hline 5 & Indonesia & 3.23 & 1.47 & 0.99 & 5.69 \\
\hline 6 & Egypt & 3.07 & 1.20 & 1.37 & 5.64 \\
\hline 7 & Philippines & 3.19 & 1.17 & 1.24 & 5.60 \\
\hline 8 & Chile & 2.41 & 1.20 & 1.89 & 5.50 \\
\hline 9 & Jordan & 2.99 & 0.91 & 1.59 & 5.49 \\
\hline 10 & Vietnam & 3.21 & 1.02 & 1.24 & 5.47 \\
\hline 11 & Mexico & 2.48 & 1.50 & 1.45 & 5.43 \\
\hline 12 & Brazil & 2.18 & 1.83 & 1.37 & 5.39 \\
\hline 13 & Bulgaria & 2.83 & 0.89 & 1.62 & 5.34 \\
\hline 14 & United States & 0.47 & 2.71 & 2.15 & 5.33 \\
\hline 15 & Ghana & 3.26 & 0.70 & 1.36 & 5.32 \\
\hline
\end{tabular}

Figura 4 - Ranking dos melhores destinos em outsourcing de TI e suporte. Fonte: A.T. KEARNEY (2009)

Nos últimos anos, o destino preferido tem sido a Índia, seguido de China e Malásia. Os preferidos na América Latina são: Chile, Brasil e México. O Brasil tem mostrado ótimo desempenho na $12^{\circ}$ posição e continuará a ser um importante ator no mercado de offshore.

Somente no Brasil, o mercado de terceirização de serviços de $\mathrm{Tl}$ deve crescer entre $10 \%$ e $12 \%$ em 2009 , de acordo com pesquisa realizada pela consultoria norte-americana Gartner e publicada em (CAETANO, 2009). O Brasil vem ganhando espaço em relação à Índia principalmente por possuir 
uma melhor infraestrutura, ambiente político e econômico mais estável e maior compatibilidade cultural com a Europa e Estados Unidos, como relata o vice-presidente de pesquisas do Gartner, lan Marriot.

As organizações estão em busca de redução de custos, aumento de produtividade, aquisição de novos mercados e melhoria contínua na prestação de serviços. Para isso, elas têm se apropriado de uma ferramenta estratégica para atingir estes objetivos: o desenvolvimento distribuído de software - significa que o desenvolvimento do software é distribuído através de diversos pontos geográficos que podem ser localizados em diferentes países/continentes.

Desenvolver softwares de forma distribuída requer um esforço das corporações para adaptar seus processos, ferramentas e sua cultura organizacional para que possam ter condições de transpor as barreiras geradas pela distância entre as equipes participantes e absorver vantagens sobre as oportunidades geradas por este ambiente.

\subsection{Definição de desenvolvimento global de software}

A definição de desenvolvimento global de software, por si só, aponta para uma clara distinção em relação ao desenvolvimento tradicional: a distância entre as equipes envolvidas no projeto. Carmel (1997) afirma que desenvolvimento global ocorre quando duas ou mais equipes estão separadas por fronteiras nacionais e atuam de forma colaborativa em projetos comuns.

A literatura relata evidências de que quando a distância entre atores em ambientes distribuídos atinge trinta metros ou mais, a comunicação natural e espontânea decresce para um nível equivalente a distâncias de milhares de metros (HERBSLEB, 2007).

O desenvolvimento global de software é um caso especial de desenvolvimento distribuído onde os atores envolvidos encontram-se dispersos em países e continentes diferentes. Outras possíveis formas de 
dispersão dos atores em ambientes de desenvolvimento distribuído também são descritos por Audy e Prikladnicki (2008):

- Distância Nacional: atores localizados dentro de um mesmo país. A interação física pode ocorrer em curtos intervalos de tempo. Dependendo do país, pode ocorrer diferença de fuso horário e conflitos culturais em escala maior que o nível anterior;

- Distância Continental: atores localizados em países diferentes, porém no mesmo continente. Interação fica mais limitada devido à distância física. Além disso, o fuso horário tem uma influência maior.

\subsection{Modelos de negócios em desenvolvimento global de software}

Utiliza-se o termo onshore para delimitar quando um processo de negócio de uma empresa é realizado no país onde está localizada sua matriz. Em contrapartida, um termo comumente utilizado e que está diretamente associado ao conceito de Desenvolvimento Global de Software é o termo offshore: atividades realizadas além das fronteiras de um país. Aspray, Mayadas e Vardi (2000) definem que offshore se refere à localização geográfica onde as atividades são executadas. Ao executar atividades além das fronteiras nacionais, ou seja, em outros países, uma empresa está implementando o conceito de offshore.

O termo offshore se aplica bem aos EUA, por exemplo, porque mesmo transferindo atividades para Canadá e México, a maior parte da transferência é feita para além das fronteiras continentais, a maioria para Índia, mas também para China, Malásia, Filipinas, e vários outros países. A Alemanha, por exemplo, transfere atividades para fora do país, especialmente para a Europa Oriental, mas não há água - sem costa - para atravessar.

Graças ao crescimento significativo do setor de serviços de TI em amplitude global, especialmente no segmento de desenvolvimento de software, as 
organizações vêm buscando alternativas em outros países, caracterizando o denominado offshore sourcing, ou simplesmente offshoring. O offshoring de um processo de negócio pode acontecer de duas maneiras: insourcing ou outsourcing.

Segundo Schniederjans et al (2005), insourcing pode ser definida como a realização de atividades de negócio internamente na empresa, ou seja, alocação ou realocação de recursos internamente na mesma organização, mesmo que a alocação ocorra em localizações geograficamente dispersas.

Outsourcing significa que uma empresa envia atividades para serem realizadas por outra organização (ASPRAY; MAYADAS; VARDI, 2000). Várias atividades de outsourcing realizadas por empresas dos EUA, por exemplo, são atividades alocadas para outras empresas americanas. Halvey e Melby (2005) definem outsourcing como uma responsabilidade gerencial e operacional por uma ou mais funções de negócio não-essenciais delegada a um terceiro. Schniederjans et al (2005) apresenta as seguintes definições para outsourcing:

- "Ação de transferir algumas atividades internas e responsabilidades de decisão de uma empresa para provedores externos";

- "Contratação/aquisição de produtos ou serviços de fontes externas à organização".

As definições acima possuem o consenso de que outsourcing envolve a alocação ou realocação de atividades de negócio (serviços ou atividades de produção) de uma fonte interna para uma fonte externa, ou seja, terceirizar atividades ou projetos para outra empresa. Vários modelos de negócios surgiram a partir das necessidades específicas das empresas. A figura 5 apresenta uma adaptação do modelo apresentado por Audy e Prikladnicki (2008) para ambientes de desenvolvimento globalmente distribuídos. 


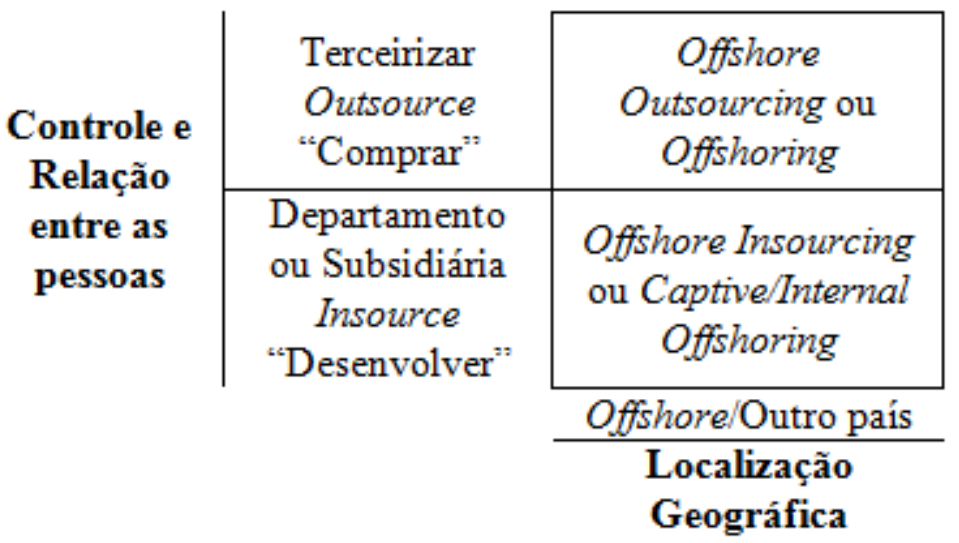

Figura 5 - Modelos de negócios em DGS, adaptado de Audy e Prikladnicki (2008)

\subsection{Fatores motivacionais ao desenvolvimento global de software}

Vários segmentos da indústria têm mostrado exemplos de como a globalização rapidamente se tornou uma prática comum e significante, tais como os setores de manufatura, indústria automotiva, finanças, entre outros. Impulsionados por avanços tecnológicos, acessibilidade de transportes, oportunidades de negócios em escala global, telecomunicações em alta velocidade, além de outros vários outros atrativos econômicos e sociais, as empresas tem tido a oportunidade de expandir seus negócios e seus lucros.

As empresas de tecnologia e desenvolvimento de software também estão em constante adaptação a esta nova estrutura, cada vez mais distribuindo atividades pelo mundo, através de ações de colaboração tanto internamente na corporação quanto externamente com parceiros, subsidiárias, e provedores de serviços terceirizados (FRYER; GOTHE, 2008).

O objetivo das empresas que adotam desenvolvimento global de software é buscar capitalização através dos diversos atrativos que este cenário proporciona. Nas subseções a seguir serão apresentados os fatores motivacionais ao DGS. 


\subsubsection{Demanda por software e mão-de-obra especializada}

A demanda por software continua crescendo mais que a capacidade de supri-la. Historicamente, a demanda por software tem superado a disponibilidade de pessoas que os desenvolvem (KAROLAK, 1998). À medida que aumenta a disponibilidade dos computadores, aumenta também a demanda por software para suprir esta necessidade. Porém, a disponibilidade de profissionais que possam suprir essa demanda não acompanha este crescimento.

\subsubsection{Redução de custos de desenvolvimento}

Como relatado por Karolak (1998), até o início dos anos 80, algo em torno de $80 \%$ de todos os softwares do mundo eram produzidos nos EUA, e a maioria da mão-de-obra deste mercado encontrava-se neste país. Porém, em meados dos anos 90, a necessidade por estes profissionais cresceu a tal ponto que os recursos locais não foram suficientes para atender a demanda. Os custos de mão-de-obra local cresceram muito a partir do momento em que as empresas começaram a competir por estes recursos, gerando uma conseqüente elevação dos custos de contratação destes profissionais.

Graças ao processo de globalização, talentos equivalentes começaram a ser descobertos em outros países, e o mais atraente para as empresas: a um custo reduzido. Com isso, países como Índia e China, com superpopulações e que injetam no mercado milhares de profissionais todos os anos, começaram a ter uma visibilidade sem precedentes.

Uma das razões mais óbvias para as empresas decidirem investir num empreendimento desafiador e arriscado como o DGS é, não surpreendentemente, o potencial dos custos de desenvolvimento que podem ser aplicados (CONCHÚIR et al., 2009). A possibilidade de transferir parte das atividades de desenvolvimento de software para países com baixo custo 
de mão-de-obra, é sem dúvida um excelente fator motivador para as empresas, que podem realizar a mesma atividade por uma fração do custo original.

\subsubsection{Acesso ao mercado global}

Segundo apresentado na figura 6, extraída de um relatório do IDC (IDC, 2008), em 2008 o mercado mundial de TI movimentou o equivalente a US\$ 1,44 trilhões, sendo US\$ 471 bilhões somente nos EUA. Na Índia, o crescimento em relação ao ano anterior é de $18 \%$, onde foi movimentado um montante de US\$20 bilhões. O Brasil também mostra um crescimento em relação a 2007 de 11\%, quando movimentou US\$ 24 bilhões. Ou seja, o mercado está mudando de predominantemente norte-americano para um mercado global, com diversos outros países atuando neste cenário mundial. Com o objetivo de ter acesso a novos mercados, principalmente o mercado global, muitas empresas buscam o desenvolvimento global de software. Outro fator motivador está relacionado à necessidade de melhor satisfazer o mercado consumidor, com isso inúmeras empresas definem a estratégia de estar próximo ao cliente, com a meta de melhorar a prestação de serviços de venda, projeto e manutenção de software, além de conhecer melhor este cliente e as condições que o cercam. 


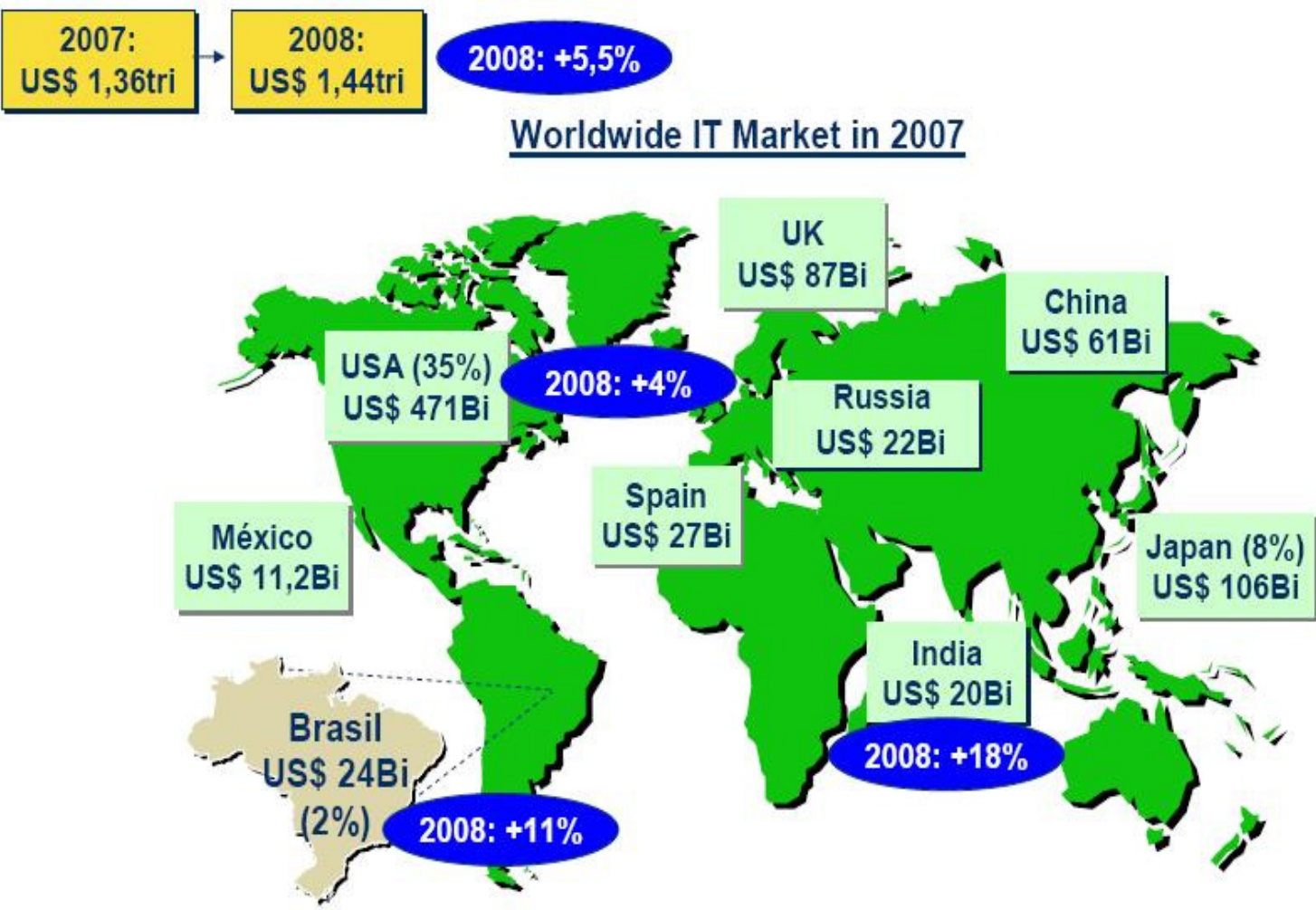

Figura 6 - Mercado mundial de TI em 2007. Fonte: IDC (2008)

Para alcançar este objetivo, as empresas tem se modificado, implementando diversas ações de negócios, tais como parcerias estratégias e joint-ventures. Dada a profundidade das relações entre as empresas e a importância do software para operacionalização de negócios e produtos, é provável que as empresas irão de alguma forma atuar com DGS.

A seguir, são apresentadas algumas ações de negócios:

\section{- Parcerias Estratégicas/Alianças}

Uma parceria estratégica, também denominada aliança, pode solicitar que um produto já existente seja modificado ou mantido por outras empresas que não aquela que o desenvolveu. Neste modelo, as interfaces entre os consumidores e o feedback de como o software atende suas necessidades são divididas entre os parceiros. Ocasionalmente, um parceiro pode ser responsável pelo desenvolvimento e manutenção, enquanto outro pode atuar junto aos consumidores. 


\section{- Joint-Ventures}

A maioria das joint-ventures resulta na formação de uma empresa separada, que possui responsabilidades fiscais junto aos parceiros da joint-venture. Este é o principal diferencial em relação a uma parceria estratégica. Neste modelo, quanto da joint-venture cada parceiro possui, determina sua influência e atividades. Um parceiro pode fornecer atividades e capital para equipamento, enquanto outros provêem recursos técnicos. Outro parceiro pode fornecer expertise em um tipo de tecnologia, tais como projetos de interface gráfica, enquanto outro fornece outra tecnologia, como gerenciamento de banco de dados.

\section{- Empresas Globais}

Empresas globais realizam o desenvolvimento conjunto de um produto entre suas divisões, a mesma divisão em diferentes localizações, ou várias empresas sob uma empresa-matriz.

Algumas empresas globais montam seus próprios centros de desenvolvimento, conhecidos como dedicated captive centers, em locais de baixo custo - o sucesso dessa subsidiária ou divisão é medido em termos da quantidade de lucro que ela retorna às matrizes.

\subsubsection{Uso otimizado do fuso-horário}

A crescente competitividade do mercado globalizado gerou um senso de urgência na disponibilização de novos produtos. É com objetivo de atenuar esta pressão criada pelo mercado, que se torna cada dia mais necessário reduzir o time-to-market, citado por Carmel (2009) como o intervalo de tempo compreendido entre a concepção de um produto até sua disponibilização para uso ou venda. Para a indústria de software esta redução é importante, principalmente em segmentos como o de telefonia móvel e sistemas de comércio eletrônico, entre outros.

Através da filosofia follow-the-sun é possível encontrar desenvolvedores trabalhando em fusos-horários diferentes e, conseqüentemente, aumentar o 
número de horas diárias trabalhadas, o que pode reduzir o tempo de um ciclo de desenvolvimento. Follow-the-sun é definido por Carmel (2009) como:

[...] um tipo de fluxo global de conhecimento, desenvolvido com objetivo de reduzir a duração do projeto, no qual o produto de conhecimento é atribuído e desenvolvido por um time e transferido diariamente para o próximo time que está vários fusos-horários além para dar continuidade àquela atividade.

O desenvolvimento follow-the-sun, também chamado de round-the-clock, pressupõe a existência das seguintes características:

- As equipes de projeto estão em fusos-horários distantes;

- Um dos principais objetivos é a redução da duração da atividade/redução do time-to-market;

- A cada instante do tempo apenas uma equipe atua sobre o produto;

- A transferência das atividades deve ser conduzida diariamente, onde esta transferência é definida como uma certificação de uma unidade de trabalho para que esta esteja disponível para a próxima equipe dar continuidade.

A figura 7 expressa graficamente a definição do conceito do desenvolvimento follow-the-sun: 


\section{Follow-the-sun 浑近}

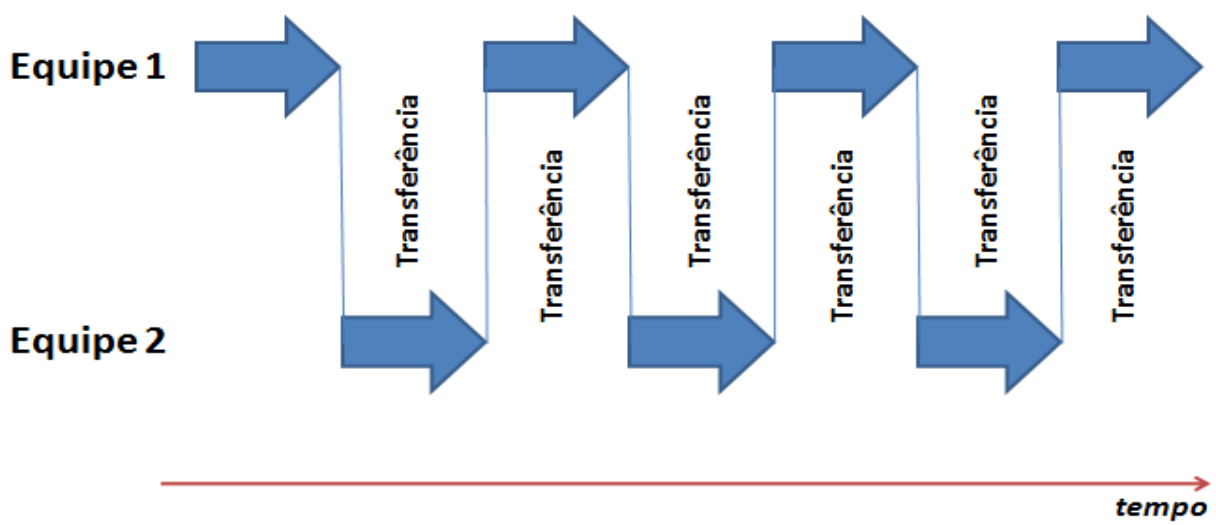

Figura 7 - Desenvolvimento follow-the-sun, adaptado de Carmel (2009)

\subsubsection{Colaboração e inovação}

A interatividade entre os diversos times de desenvolvimento espalhados pelo mundo sugere a ocorrência do aumento de inovação e compartilhamento de melhores práticas entre seus participantes. Equipes de diferentes lugares, formando um grupo globalizado, interagindo a partir de países distintos, proporcionam uma miscelânea cultural que pode gerar oportunidades de observar pontos de vistas alternativos e formas distintas de resolução de problemas.

\subsection{Desafios do desenvolvimento global de software}

Ao incorporar ao processo de desenvolvimento de software características de dispersão geográfica, distância temporal e as diferenças culturais entre os atores participantes, novos desafios se tornam presentes. Essas características geram necessidades e tecnologias distintas do desenvolvimento com equipes presentes no mesmo espaço físico e, conseqüentemente, detalhes que pertencem a essa forma de desenvolvimento. 


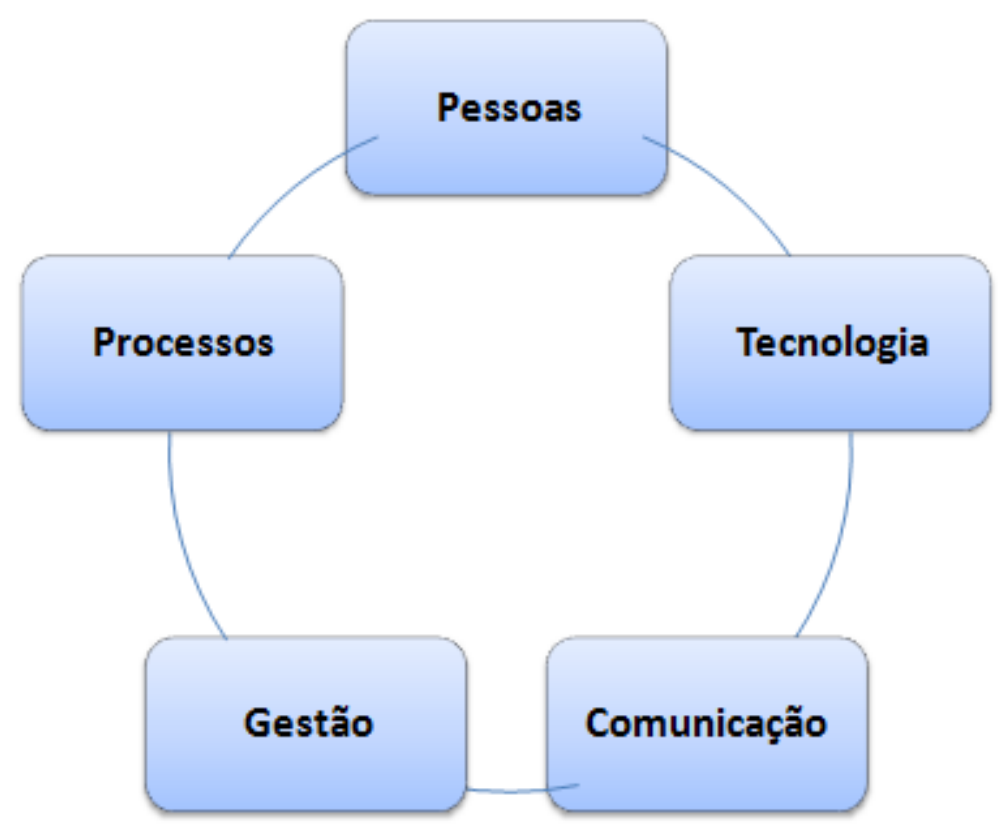

Figura 8 - Categorias de desafios do DGS

Os principais desafios de DGS podem ser agrupados em categorias, conforme apresentado na figura 8, uma adaptação de Audy e Prikladnicki (2008, p. 61):

- Pessoas: características que afetam diretamente os recursos humanos envolvidos no processo de desenvolvimento de software;

- Processos: características que influenciam na forma como o projeto será desenvolvido;

- Gestão: desafios relacionados aos aspectos organizacionais envolvidos no desenvolvimento distribuído;

- Comunicação: desafios que contribuem para o relacionamento e a gestão da infraestrutura das equipes de projeto e os stakeholders envolvidos em projetos de DGS;

- Tecnologia: as diversas ferramentas e recursos tecnológicos que podem apoiar o desenvolvimento de software.

Os principais desafios de cada uma das categorias supracitadas serão abordados nas seções seguintes. 


\subsubsection{Desafios relacionados à categoria Pessoas}

\section{Confiança}

O desenvolvimento de software é uma atividade que envolve pessoas, e por esta razão envolve confiança. É necessário que os membros dos times tenham confiança entre si, visto que suas atividades dependem umas das outras.

Um estudo realizado por Al-Ani e Redmiles (2009) revela que em projetos de DGS a confiança é um item crítico, principalmente devido a questões como: tamanho e diversidade da equipe, características do projeto e da liderança. Quanto maior o tamanho da equipe, maior a dificuldade de estabelecer uma relação de confiança.

A cooperação entre as pessoas é considerada fator crucial para a sobrevivência das organizações e a confiança é o coração dessa cooperação. Ela é importante para que as pessoas trabalhem de forma efetiva e compartilhem informações e conhecimento de forma aberta, gerando a possibilidade de aumento da segurança e convicção das relações interpessoais (AL-ANI; REDMILES, 2009).

Herbsleb e Grinter (1999) apresentam o resultado de um estudo empírico com pólos de desenvolvimento observados no Reino Unido e Alemanha: inicialmente os grupos possuíam pouca interação e baixo grau de confiança, muito devido a falhas na interpretação correta do comportamento mútuo. Porém, quando parte do grupo inglês participou de reuniões fisicamente junto ao grupo alemão, com objetivo de atuar nas dificuldades de relacionamento, o resultado foi uma mudança considerável nas relações entre as equipes, com maior cooperação e compreensão dos envolvidos.

\section{Diferenças culturais}

Segundo MacGregor, Hsieh e Krutchen (2005), cultura é o conjunto dos valores e comportamentos aprendidos e compartilhados por um grupo de pessoas. A diversidade cultural presente entre as equipes, tais como os diferentes idiomas e a cultural local afetam a colaboração. Além disso, existe 
a influência das culturas organizacional e funcional, as quais têm um impacto significante na geração de um senso comum entre os times.

No caso da cultura organizacional, estão envolvidas questões como normas e valores das organizações envolvidas. Na cultura funcional incluem-se fatores relacionados à cultura de desenvolvimento de sistemas, tais como a adoção de metodologias e práticas de gerenciamento de projetos. As diferenças culturais irão refletir muitas vezes na forma como as equipes lidam com itens como hierarquia organizacional, forma de comunicação e orientação em relação ao processo de desenvolvimento.

Casey (2009) apresenta resultados de um estudo de três anos realizado entre profissionais de uma multinacional que dividiu parte do seu processo de desenvolvimento entre Irlanda e Malásia. O estudo identifica as implicações de interpretar incorretamente ou não dar a devida atenção às diferenças culturais, onde questões culturais como o sexo do profissional, religião e comportamentos proativos tiveram grande impacto no sucesso de projetos.

Borchers (2003) analisou durante quatro anos dois projetos de desenvolvimento de software com contribuições de técnicos da Índia, Japão e Estados Unidos. O autor avaliou os fatores culturais:

- Hierarquia: capacidade de aceitar e respeitar a hierarquia organizacional;

- Tolerância a incertezas: aceitação de incertezas futuras;

- Individualismo: grau de independência de um membro da equipe em relação ao grupo.

O resultado apresentado mostra que os fatores culturais tiveram profundo impacto nos esforços em engenharia de software dos projetos. Inicialmente, tinha-se a idéia que um processo de software rígido poderia amenizar as diferenças culturais. Porém, o sucesso só foi possível ao adaptar e ajustar as expectativas do projeto às realidades dos impactos culturais.

Uma alternativa adotada por algumas empresas para reduzir os impactos culturais é o papel do liaison, um membro da equipe deslocado para estar 
em convívio físico por um período de tempo com outra equipe. A experiência adquirida pelo liaison após vivenciar outra cultura gera oportunidades para que ele possa facilitar a comunicação entre seu grupo original e o grupo com o qual conviveu, promovendo uma troca de informações mais produtiva, gerenciando conflitos e mal-entendidos, além da oportunidade de aumentar a confiança entre as equipes (HERBSLEB; GRINTER, 2001).

Um conceito similar ao liaison e que ajuda a solucionar as lacunas culturais entre as equipes é o de proxy: um indivíduo "bicodificado", com condições de operar facilmente em duas culturas distintas (KRUCHTEN apud BROCKMANN; THAUMULLER, 2009). Trata-se de alguém que nasceu e cresceu em uma determinada cultura, e que viveu e estudou uma quantidade considerável de anos em uma cultura diferente. No estudo de caso de Brockmann e Thaumuller (2009), os autores apresentam um relato empírico de uso de proxies entre chineses e alemães. Foram formados pares de membros das equipes, um "nativo" com um "proxy". O resultado foi muito satisfatório, uma vez que o proxy traduzia a diferença entre o que foi dito e o que realmente se quis dizer entre os membros chineses e alemães, além de traduzir também os conceitos culturais que os permeavam.

\section{Senso de Equipe}

Quando se usa o termo equipe logo se tem a idéia de unidade, de um grupo co-localizado, homogêneo, confiança, padrões de comunicação e com poucos membros (AUDI; PRIKLADNICKI, 2008). Porém, é difícil imaginar tais características ao incluir fatores como dispersão geográfica e temporal, além das diferenças culturais, como relatado por Kommeren e Parviainen (2007), ao descrever alguns problemas decorrentes dessa dispersão, tais como dificuldades de gerenciamento da equipe e comunicação entre eles.

\subsubsection{Desafios relacionados à categoria Processos}

\section{Engenharia de Requisitos}

A engenharia de requisitos é um processo que envolve interação entre pessoas e no DGS elas estão dispersas geograficamente. Damian e Zowghi 
(2003) relacionam as principais dificuldades enfrentadas pela área de engenharia de requisitos devido às características do DGS, a saber:

- Diversidade na cultura do cliente e na sua área de negócios;

- Dificuldade de interação apropriada entre os usuários e a equipe técnica;

- Falta de comunicação informal e pouca percepção do contexto local de trabalho;

- Nível de confiança reduzido;

- Dificuldade em gerenciar conflitos e gerar discussões entre os membros da equipe;

- Dificuldade em alcançar um senso comum sobre os requisitos;

- Reuniões de tomada de decisão não-produtivas;

- Atraso na execução de atividades.

Para mitigar estas dificuldades, Damian (2007) apresenta as seguintes estratégias:

- Definir uma estrutura organizacional transparente com responsabilidades de comunicação para o projeto, através da criação de papéis com responsabilidades bem definidas, atribuição dos papéis entre os stakeholders distribuídos, e indicações de que papéis devem se comunicar entre si entre os diferentes grupos;

- Estabelecer conexões ponto-a-ponto em todos os níveis de gestão, de projeto e de equipe entre todos os times distribuídos. O objetivo é contatar os papéis apropriados no grupo de stakeholders remoto para permitir uma elicitação e validação de requisitos efetiva;

- Sincronizar processos inter-organizacionais e realizar interações e entregas com freqüência. Para alcançar um entendimento comum, os requisitos devem ser constantemente validados, e se alinhar os processos de engenharia de requisitos entre os múltiplos times é difícil, definir e compartilhar conhecimento sobre os artefatos de trabalho tem 
seus benefícios. Isso gera nas equipes a visibilidade do progresso do trabalho dos stakeholders nos times remotos;

- Estabelecer liasions culturais: são papéis importantes para o estabelecimento de relacionamentos, assim como na elicitação e validação de requisitos quando lidando com conhecimento tácito sobre a prática de trabalho e características culturais de uma determinada equipe.

- Manter canais de comunicação abertos entre estes papéis dos stakeholders. Reuniões envolvendo representantes de todos os grupos de stakeholders são importantes para alinhar os objetivos do projeto, estabelecer os artefatos de trabalho comuns, e seu mapeamento com os requisitos e planos de gestão de riscos (DAMIAN; ZOWGHI, 2003), (SMITE; 2006 apud DAMIAN, 2003), (EBERT; NEVE, 2001 apud DAMIAN, 2003).

\section{Gerência de Configuração}

O propósito da gerência de configuração de software é estabelecer e manter a integridade de produtos de software ao longo do ciclo de vida do projeto Inclui identificar a configuração do software em um dado instante do tempo, controlar sistematicamente as mudanças na configuração, e manter a integridade e rastreabilidade da configuração por todo o ciclo de vida do projeto (PILATTI et al., 2006).

Realizar essas tarefas em um projeto distribuído é uma tarefa crítica, pois envolve um controle intenso nas modificações dos artefatos e sincronismo com as diversas localidades envolvidas. Lanubile et al. (2010) apresenta uma tabela com diversas ferramentas para controle de versões de artefatos, coletadas a partir da revisão literária dos recentes eventos de DGS e também de consultas à indústria que atua ativamente em projetos dessa natureza. 


\section{Processo de Desenvolvimento}

Herbsleb e Grinter (1999) apresentam um estudo empírico em DGS em que problemas de gerenciamento do projeto ocorrem devido ao uso de processos de desenvolvimento distintos nos diferentes times, além de dificuldades de integração e uma linguagem comum. Carmel (2001) sugere a institucionalização de um processo de desenvolvimento comum para solucionar este problema. $\mathrm{O}$ autor afirma que a adoção de um processo unificado de desenvolvimento pode prevenir vários problemas em um ambiente de DGS, auxiliando a reduzir conflitos e interpretações incorretas, uma vez que itens como, por exemplo, artefatos a serem produzidos e marcos de projeto, são definidos previamente.

\subsubsection{Desafios relacionados à categoria Gestão}

\section{Gerenciamento de Projetos}

A gerência de projetos exige adaptações de técnicas utilizadas em projetos co-localizados, de forma a suportar e reduzir as dificuldades impostas pela dispersão geográfica das equipes (ZANONI; AUDY, 2004 apud AUDY; PRIKLADNICKI, 2008).

É importante que o gerente tenha uma leitura correta do projeto em relação ao DGS, pois, dependendo das características do projeto, as adaptações poderão ser aplicadas em maior ou menor quantidade. Siqueira (2005) apresenta em seu trabalho um conjunto de recomendações para a gestão de projetos em ambientes de DGS, e ressalta a importância de avaliar as características do projeto, visto que fatores como cultura regional e nível de dispersão das equipes, por exemplo, influenciam na forma como o projeto será conduzido.

\section{Gerenciamento de Riscos}

O propósito do processo de gerenciamento de riscos é identificar problemas potenciais antes que estes ocorram de tal forma que as ações de mitigação possam ser planejadas e acionadas quando necessário ao longo do tempo 
de vida do produto ou projeto para mitigar impactos adversos ao alcance das metas estabelecidas (CMMI, 2006).

Persson e Mathiassen (2010) elaboraram um processo para gerenciar riscos em equipes distribuídas baseado nas práticas do mesmo processo presente no modelo $\mathrm{CMMI}^{3}$. Duas práticas presentes na proposta dos autores são: desenvolver e implementar planos de mitigação de riscos. Estas ações estão presentes em projetos com equipes co-localizadas. Porém, os autores estenderam essa abordagem para atender as características do DGS.

\subsubsection{Desafios relacionados à categoria Comunicação}

\section{Contextualização}

No cenário de equipes distribuídas, não é comum que as equipes tenham conhecimento sobre questões do dia-a-dia de outras equipes participantes. Por exemplo, Audy e Prikladnicki (2008) citam a questão de uma equipe não ter conhecimento de que outra equipe integrante do projeto não irá trabalhar em um determinado dia, pois se trata de um feriado nacional.

Esse exemplo e outros vários estão relacionados a questões específicas do ambiente onde uma determinada equipe está inserida e como tais questões influenciam no projeto. Algumas soluções adotas pelas empresas para este problema são: inserção de uma intranet com informações relevantes sobre cada centro, mensagens automáticas sobre ausência de pessoas, ou até mesmo treinamentos sobre compartilhamento de contexto entre os integrantes do projeto (AUDY; PRIKLADNICKI, 2008).

\section{Estilo de Comunicação}

A forma como as pessoas se comunicam está relacionada a sua cultura. Herbsleb e Grinter (1999) relatam o caso das diferenças entre alemães e ingleses. Os alemães são mais diretos na comunicação e os ingleses realizam uma abordagem mais polida, mais comedida. Eles afirmam no estudo que tais diferenças influenciam na habilidade da equipe de se

\footnotetext{
${ }^{3}$ CMMI - Capability Maturity Model Integration - é um modelo de maturidade de melhoria de processos para o desenvolvimento de produtos e serviços.
} 
comunicar, criando mal-entendidos, comunicação inadequada, falta de confiança, e por fim, uma conseqüente queda na produtividade do projeto.

\section{Idioma}

Este é um dos problemas mais óbvios de se identificar, uma vez que as equipes são geralmente formadas em diferentes nações, o que muitas vezes significa idiomas distintos. Mesmo em projetos com equipes que falam o mesmo idioma, ainda assim há problemas nas formas distintas como as pessoas se expressam, o que pode gerar falhas de interpretação.

Damian e Zowghi (2003) afirmam que a linguagem do cliente é um fator crítico e que impacta diretamente atividades como elicitação e validação de requisitos, uma vez que a barreira do idioma afeta a transferência de conhecimento dos requisitos para os analistas de sistemas.

Lutz (2009) apresenta um estudo realizado em empresas multinacionais, onde a língua inglesa foi utilizada como padrão internacional de colaboração, apesar do alemão ser a língua oficial no país onde a empresa está sediada.

Fusos Horários

Para os casos de projetos que atuam com equipes em fusos horários distantes, este pode se tornar um item problemático. Afinal, podem ocorrer casos onde uma equipe está começando a jornada de trabalho e a outra terminando. Como elas irão interagir? Como uma equipe em Londres poderá, pela manhã, contatar um stakeholder em São Paulo, com um fuso horário de -4 horas? Se em Londres for 9 horas da manhã, o cliente em São Paulo estará provavelmente dormindo, pois lá ainda serão 5 horas da manhã.

Existem soluções que aplicam o conceito do desenvolvimento follow-the-sun, como apresentado por Carmel, Dubinsky e Espinosa (2009). Porém, alguns autores questionam a eficiência dessa solução (CONCHUIR et al., 2009).

\subsubsection{Desafios relacionados à categoria Tecnologia}


As tecnologias colaborativas devem ser ferramentas amplamente utilizadas no DGS para minimizar os impactos da dispersão geográfica entre os atores. Lanubile et al. (2010) apresenta uma série de ferramentas que vêem sendo amplamente utilizadas para apoiar o desenvolvimento em equipes de DGS, como:

- Sistemas de controle de versão;

- Rastreadores;

- Ferramentas para integração de código;

- Ferramentas de modelagem;

- Ferramentas de gestão de conhecimento;

- Ferramentas de comunicação e aplicações web 2.0.

Outros exemplos incluem o uso de mensagens instantâneas (NIINIMAKI; LASSENIUS, 2008), Social Software ${ }^{4}$ (ABBATTISTA et al, 2008) e ferramentas para projeto distribuído de software (CATALDO et al., 2009).

Telecomunicações

A infraestrutura de telecomunicações é um desafio latente, uma vez que para uma comunicação efetiva é necessária alta disponibilidade desse tipo de recurso, conexões confiáveis e de alta velocidade.

\footnotetext{
${ }^{4}$ Termo geral para definir uma série de ferramentas e aplicações que permitem interação de grupos e comunicação mediada por computadores.
} 


\section{ENGENHARIA DE REQUISITOS}

A engenharia de requisitos é a disciplina que procura sistematizar o processo de definição de requisitos. Essa sistematização é necessária porque a complexidade dos sistemas exige que se preste mais atenção ao correto entendimento do problema antes do comprometimento de uma solução (LEITE, 1994).

A engenharia de requisitos é um processo multidisciplinar, rico em comunicação e centralizado em pessoas. Nuseibeh e Easterbrook (2000) definem a como o processo de descoberta do propósito para o qual um software é esperado, através da identificação de seus stakeholders ${ }^{5}$ e suas necessidades, documentando-as de tal forma que sejam de fácil análise, comunicação e subseqüente implementação.

Zave (1997) apresenta a seguinte definição para engenharia de requisitos:

A engenharia de requisitos é o ramo da engenharia de software envolvido com metas do mundo real para as funcionalidades e restrições de sistemas de software. Além disso, trata do relacionamento desses fatores com especificações precisas do comportamento do software, e sua evolução ao longo do tempo e entre famílias de software. (ZAVE, 1997, tradução do autor).

Para Nuseibeh e Easterbrook (2000), a definição de Zave (1997) está voltada para engenharia de software. Todavia, o software não funciona de forma isolada do sistema sob o qual está inserido, e, portanto, a engenharia de requisitos deve cobrir uma visão em nível de sistema. Dessa forma, como os próprios autores afirmam, é mais adequado caracterizar a engenharia de requisitos como um ramo da engenharia de sistemas, cujo objetivo final é a entrega de comportamentos do sistema para seus stakeholders.

A importância da engenharia de requisitos tem sido cada vez mais reconhecida na indústria de software, mas ainda é difícil afirmar que os resultados das pesquisas em engenharia de requisitos estão sendo

\footnotetext{
${ }^{5}$ Pessoa ou entidade que tenha interesse nos requisitos ou influencia na definição destes.
} 
amplamente utilizados. Katama (2007) aponta o famoso Chaos Report, relatório resultante de uma pesquisa conduzida pelo Standish Group em 1994, como uma fonte repetidamente citada quando se debate sobre causas de fracassos e sucessos em projetos de software. O impacto dos números apresentados no relatório foi muito forte, visto que a taxa de falhas em projetos de software apresentada alcançou os expressivos $70 \%$.

O relatório apresenta alguns fatores que conduziram ao sucesso ou ao fracasso, baseado numa pesquisa realizada junto a gerentes executivos de TI quando questionados sobre suas opiniões acerca dos motivos que levam os projetos a falharem ou a obterem êxito. O resultado: "Definições transparentes dos requisitos" foi o terceiro no ranking de fatores que conduzem a projetos de sucesso (com 13\%), e "Requisitos incompletos" foi o primeiro no ranking de fatores (com 13,1\%) que conduzem ao fracasso de projetos.

Trata-se de um estágio crítico no desenvolvimento de software, pois é neste estágio que o propósito, funcionalidades, e limites do software devem ser totalmente identificados, analisados e definidos. Nos últimos anos, identificou-se que problemas relacionados à coleta, análise, especificação e gestão de requisitos estão entre as principais razões para falhas em projetos de software, onde o produto final não atende às necessidades dos proprietários dos problemas (ZOWGHI; PARYANI, 2003).

Kotonya e Sommerville (1998) afirmam que o custo para corrigir erros de definição de requisitos pode ser até cem vezes maior que o custo de correção de um erro de programação. Os autores apresentam um número de conseqüências que surgem quando os requisitos de um sistema estão incorretos:

- O sistema será entregue após o prazo previsto e irá custar bem mais do que o previsto;

- Os clientes e usuários finais não estão satisfeitos com o sistema. Eles certamente não irão utilizar suas facilidades ou podem até decidir desconsiderá-lo completamente; 
- O sistema pode não ser confiável em seu uso, com erros de sistema regulares e interrupções abruptas durante sua operação;

- Caso o sistema continue em uso, os custos de manutenção e evolução do sistema geralmente são muito altos.

\subsection{Definição de requisitos}

Os requisitos estão relacionados ao comportamento esperado de um sistema. Kotonya e Sommerville (1998) afirmam que os requisitos são descrições de como o sistema deve se comportar, informações sobre o domínio da aplicação, restrições quanto à operação do sistema, ou especificações sobre propriedades ou atributos do sistema. Os requisitos são definidos durante as fases iniciais do desenvolvimento de um sistema como uma especificação do que deve ser implementado.

Segundo a norma IEEE Standard 610.12-1990 (IEEE, 1990, p. 62), requisitos são definidos como:

(1) Uma condição ou capacidade necessária para um usuário solucionar um problema ou atingir um objetivo;

(2) Uma condição ou capacidade que precisa ser atendida ou atingida por um sistema ou componente do sistema, para satisfazer um contrato, padrão, especificação ou outro documento formalmente imposto;

(3) Uma representação documentada de uma condição ou capacidade como em (1) ou (2).

\subsection{O processo de engenharia de requisitos}

A norma IEEE Standard 610.12-1990 (IEEE, 1990, p. 57) apresenta a seguinte definição para processo: uma seqüência de passos executados para um determinado propósito. A obtenção dos requisitos junto aos stakeholders e sua correta definição em uma especificação de requisitos requerem a execução ordenada de várias atividades, o que constitui um processo. 
A figura 9 apresenta o modelo em espiral do processo de engenharia de requisitos proposto por Kotonya e Sommerville (1998), uma adaptação do modelo do processo de desenvolvimento de software originalmente proposto por Boehm (1988), iniciando com execução de atividades de levantamento ou elicitação de requisitos, seguida pela análise e negociação, documentação e validação desses requisitos. Por se tratar de um modelo em espiral, interativo e incremental, estas atividades se repetem até que seja alcançada uma versão final do documento de requisitos.

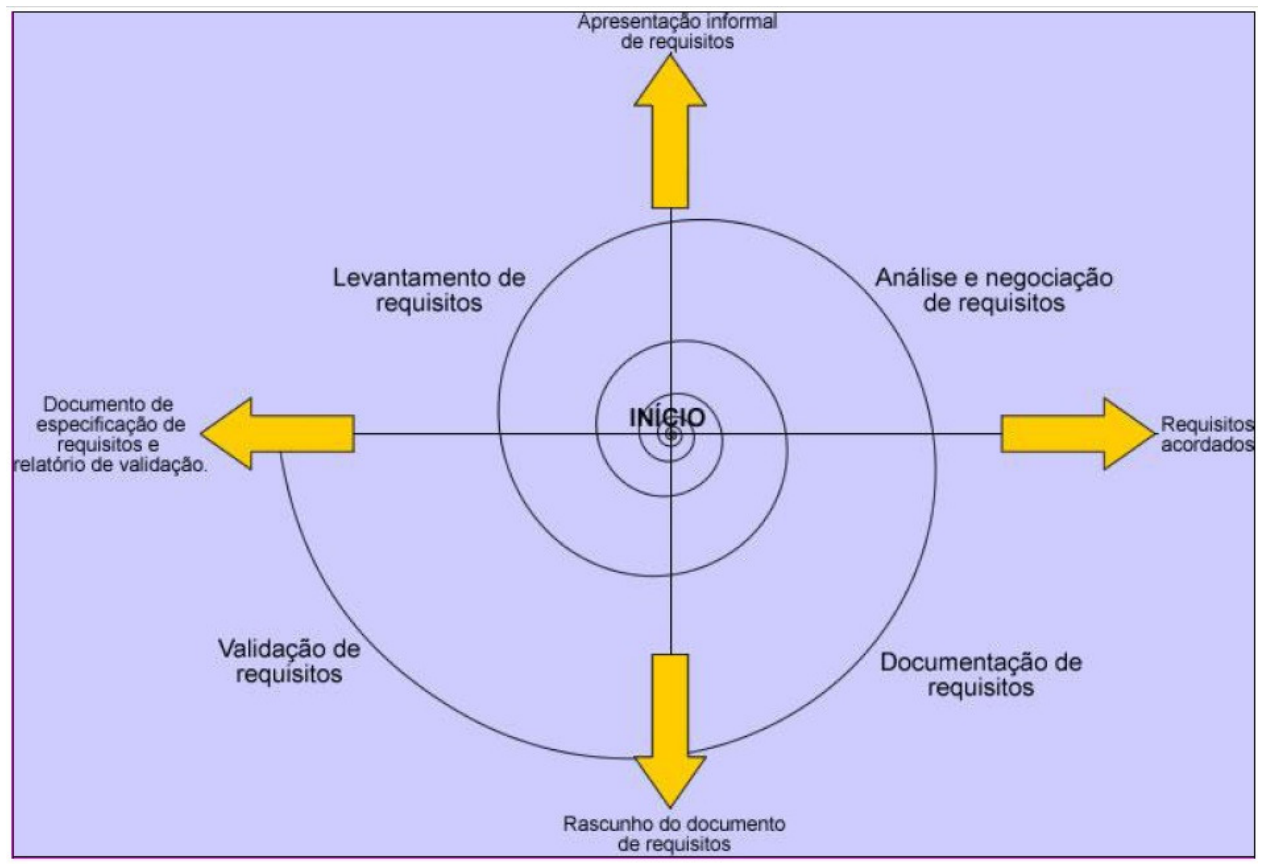

Figura 9 - Modelo em espiral para o processo de engenharia de requisitos. Fonte: Kotonya e Sommerville (1998)

O processo de engenharia de requisitos é caracterizado por quatro etapas (IEEE, 2004):

- Levantamento de Requisitos: obtenção de dados e subseqüente descoberta dos requisitos;

- Análise de Requisitos: organização e refinamento dos requisitos coletados na etapa anterior, resolução de requisitos conflitantes, criação de modelos conceituais ou de negócio; 
- Especificação de Requisitos: definição precisa dos requisitos e dos atributos de qualidade aplicáveis a cada um deles: correção, eliminação de ambigüidade, completude, consistência, modificabilidade, rastreabilidade;

- Validação de Requisitos: garantia de que os requisitos foram corretamente definidos (verificação) e que de fato satisfazem às necessidades de seus interessados (validação).

\subsection{Métodos consensuais para levantamento de requisitos}

O levantamento de requisitos é uma das atividades mais críticas no processo de desenvolvimento de sistemas (GOTTESDEINER, 2002). Uma elicitação de requisitos pobre praticamente garante que o projeto final será um completo desastre. Para melhorar esta etapa no desenvolvimento de um produto, inicialmente é importante compreender do que ela se trata. Segundo Hickey e Davis (2003) a elicitação de requisitos é, sobretudo, determinar as necessidades dos stakeholders.

O levantamento de requisitos é um sistema onde seus componentes são atividades humanas: trata-se de um processo de colaboração entre o engenheiro de sistemas $e$ as pessoas envolvidas nesse sistema (SIMONETTE, 2010).

Hitchins (2008) afirma que o engenheiro de sistemas pode se utilizar de uma variedade de métodos para auxiliar a organização, isto é, diretores, gerentes, empregados, no processo de identificação de seus próprios problemas e como vir a solucioná-los. O objetivo dos métodos consensuais é desenvolver um consenso de um grupo representativo de pessoas e, possivelmente, mais adiante, usar este grupo como aquilo que ele define como os futuros "agentes para mudança" (HITCHINS, 2008). Esses métodos são apresentados nas seções a seguir. 


\subsubsection{Brainstorming}

O brainstorming é uma técnica para resolução criativa de problemas, cujo objetivo principal é facilitar a geração de soluções originais, através da produção do maior número possível de idéias sobre um problema particular. Como a própria tradução do termo original determina, trata-se de uma "tempestade de idéias".

$\mathrm{Na}$ técnica de brainstorming, o problema que é entregue aos participantes tem um único ponto focal, que deve ser rapidamente compreendido e desenvolvido por todos. O brainstorming possui basicamente duas fases principais: a produção das idéias seguida da avaliação das idéias propostas, gerando o senso comum dos participantes.

O resultado de uma sessão de brainstorming para o processo de levantamento de requisitos pode ser uma lista de idéias, expectativas, requisitos, definições e até a identificação de um problema quanto à definição desses itens (TAGUE, 2005; HITCHINS,2008 apud SIMONETTI, 2010).

\subsubsection{Técnica de Grupo Nominal (TGN)}

Trata-se de uma técnica semelhante ao brainstorming, onde a característica fundamental é o fato dos participantes, apesar de estarem frente a frente na reunião, apresentarem suas idéias de forma sistemática e independente.

O procedimento é basicamente o seguinte:

- Geração de idéias: cada um dos participantes escreve em uma folha de papel suas idéias sobre o assunto;

- Registro das idéias: em forma de rodízio, os participantes apresentam suas idéias, até que todos tenham apresentado todas suas idéias. A cada leitura o moderador escreve a idéia em um quadro visível a todos; 
- Discussão sobre as idéias: cada idéia é então debatida, de forma a eliminar falhas de compreensão e alcançar um entendimento sobre o significado de cada idéia;

- Eleição das idéias: cada participante é convidado a definir sua priorização das idéias, através de um sistema de pontuação das idéias, de forma que ao final seja possível determinar um ranking consensual do grupo.

Essas idéias constituem as respostas do grupo para o assunto colocado e foram produzidas pelo grupo como um todo, daí o termo "grupo nominal" (TAGUE, 2005; HITCHINS,2008 apud SIMONETTI, 2010).

\subsubsection{Escrita de Idéias}

A escrita de idéias é um aprofundamento do TGN. Essa técnica explora a estratégia de estimular o surgimento de idéias dentro do grupo e busca omitir a origem de uma idéia particular, a fim de fugir de preconceitos como, por exemplo, a geração de uma idéia por alguém com pouca experiência ou por um gerente.

Esta técnica possui a seguinte estrutura:

- Os participantes escrevem suas idéias, sugestões, etc., em uma folha de papel;

- Em seguida, o moderador solicita que os participantes passem a folha para a pessoa ao lado;

- Ao receber uma folha, o participante pode ver as idéias já escritas, o que pode estimulá-lo a produzir novas idéias;

- O processo se repete até que todos tenham esgotado sua criatividade e não consigam mais produzir idéias.

- A partir daí, as listas geradas são refinadas posteriormente utilizando técnicas como brainstorming ou TGN. 


\subsubsection{Modelagem Estrutural Interpretativa de Warfield}

Proposta originalmente por J. Warfield em 1973 para analisar sistemas sociotécnicos complexos com o nome Interpretive Structural Modeling - ISM, a técnica ${ }^{6}$ apóia o trabalho em grupo multidisciplinar que o auxilia a analisar questões complexas e organizar a visão de tais questões (WRIGHT, 1995).

Hitchins (2008) afirma que o ISM tem sido descrito como um processo de aprendizagem assistida por computador que possibilita a uma pessoa ou a um grupo de pessoas, desenvolver um mapa das relações entre os elementos de uma situação complexa, provendo um entendimento da situação e fornecendo uma visão das ações possíveis para se tratar um problema.

Wright (1995) descreve uma sessão ISM conforme a seguir:

- Inicia com a caracterização do problema e formação de um grupo de pessoas com conhecimento e experiência advindos de diferentes áreas de conhecimento relacionadas. O grupo extrai do contexto do problema uma lista de elementos significativos e em seguida escolhe uma relação para mapear as inter-relações entre eles.

- A partir dessa relação formulam-se perguntas para que o grupo responda sim ou não, no ISM tradicional. À medida que as perguntas são respondidas, uma matriz vai sendo gerada, cujas linhas e colunas representam os elementos do problema $e$ na qual as células apresentam as características do relacionamento entre esses elementos.

- O resultado é um grafo, onde os nós são os elementos do problema e as relações as arestas, o qual passa a ser examinado e revisado pelo grupo, para que possa refletir uma fiel representação da visão do grupo.

\footnotetext{
${ }^{6}$ Essa técnica também é conhecida pelo termo Análise e Estruturação de Modelos (WRIGHT, 1995)
} 
- O objetivo é verificar se há, de fato, um consenso grupo acerca do resultado obtido.

\subsubsection{Metodologia de Sistemas Soft de Checkland}

A Metodologia de Sistemas Soft (Soft Systems Methodology - SSM) é uma proposta de Peter Checkland para a articulação de problemas poucos estruturados, ou seja, problemas sobre os quais as pessoas não possuem um consenso, normalmente problemas mal definidos (SIMONETTI, 2010).

A SSM trata de uma estruturação por meio de idéias de sistemas, da maneira de se pensar sobre o que seria apropriado de se fazer diante de situações sociais complexas, consideravelmente comuns no dia-a-dia das organizações, em que há uma percepção de que mudanças precisam ser feitas para aliviar as tensões envolvidas (CHECKLAND; POULTER, 2006).

A figura 10 apresenta uma representação simplificada da metodologia SSM:

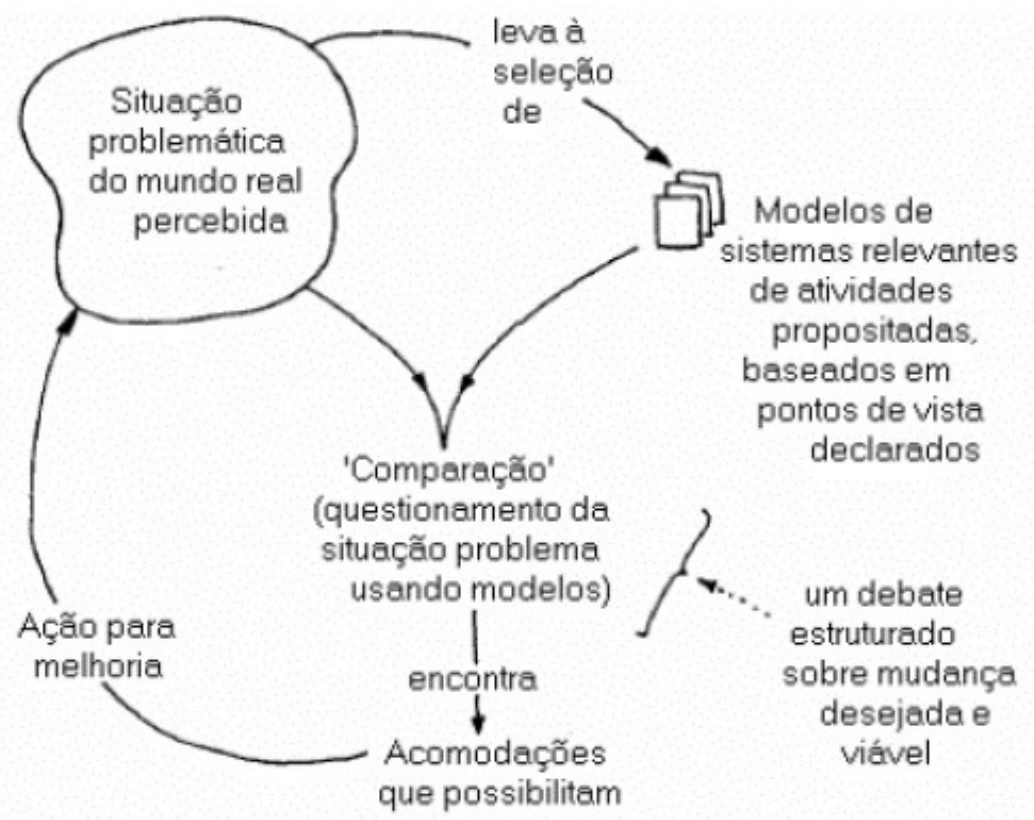

Figura 10 - Representação simplificada da metodologia SSM

O ponto de partida é uma situação problemática e que sempre envolve pessoas com diferentes pontos de vista e, conseqüentemente, percepções distintas quanto à definição do problema, dos objetivos e do que deve ser 
feito. O objetivo é levar a análise a um nível que permita evidenciar e examinar as diferentes visões de mundo às quais os diferentes atores aderem (CHECKLAND; POULTER, 2006).

A partir desse ponto, estrutura-se um debate entre diferentes indivíduos e grupos, no qual as diferentes premissas sobre o mundo sejam examinadas e discutidas. O resultado esperado não é necessariamente a criação de percepções compartilhadas, mas sim uma acomodação entre os pontos de vista e interesses conflitantes.

\subsubsection{Método Soft Rigoroso de Hitchins}

O Método Soft Rigoroso ou Rigorous Soft Method - RSM, de autoria de Derek. K. Hitchins, pode ser aplicado a qualquer contexto (SIMONETTI, 2010). As pessoas que estão vivenciando o problema e possuem conhecimento sobre ele, fornecem informações sobre este quando participam dos encontros com o engenheiro de sistemas.

A figura 11 apresenta uma representação do RSM: 


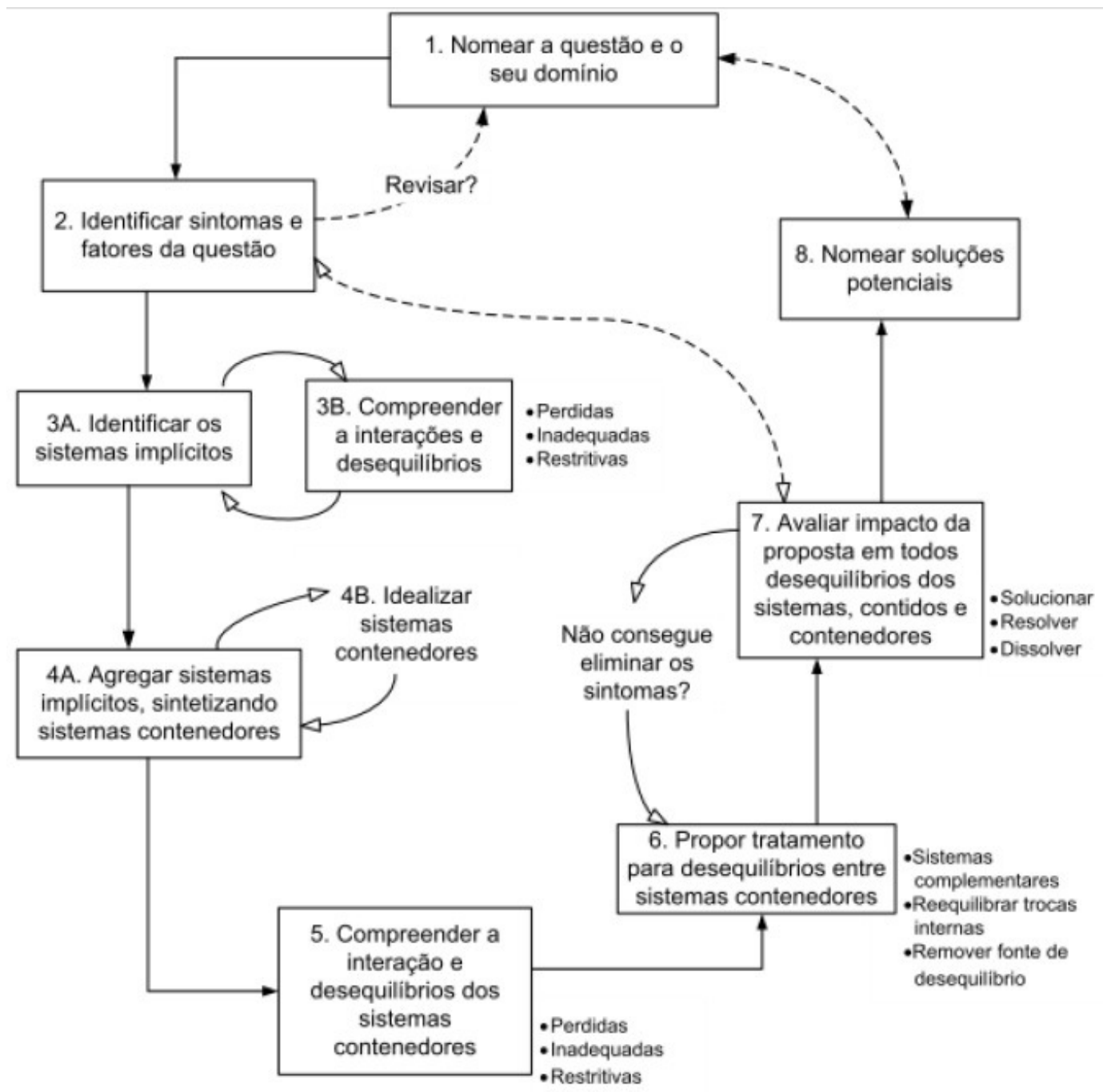

Figura 11 - Representação do RSM de D. Hitchins

Os passos estão descritos a seguir (HITCHINS, 2003, 2008 apud SIMONETTI, 2010):

1. Nomear a questão e seu domínio: identificação de uma questão de um problema, ou seja, uma preocupação a respeito de um tema ou tópico. Descreve-se a situação atual;

2. Identificar sintomas e fatores da questão: identificam-se os sintomas que apontam a natureza da questão. Os fatores da questão a identificar são os aspectos de uma questão que a tornam única.

Neste passo são realizadas entrevistas com pessoas que tenham conhecimento sobre o domínio do problema, ou seja, que possuam 
interação com o problema. Várias técnicas podem ser utilizadas neste passo, entre elas, brainstorming, TGN ou ISM.

3. Identificar sistemas implícitos: cada sintoma implica na existência de pelo menos um sistema implícito na situação do problema. São sistemas funcionais que precisam existir para que o sintoma apareça.

4. Agregar sistemas implícitos, sintetizando sistemas contenedores: os sistemas implícitos são agregados formando conjuntos, um conjunto por sintoma. Cada conjunto é um sistema contenedor implícito.

5. Compreender a interação e desequilíbrios dos sistemas contenedores: avalia-se as interações existentes entre os sistemas contenedores. O processo de agregação pode revelar potenciais desequilíbrios nessas interações.

6. Propor tratamento para o desequilíbrio entre sistemas contenedores: são utilizadas as diferenças entre o mundo ideal e o mundo real para propor soluções sociotécnicas aos desequilíbrios encontrados, com objetivo de neutralizar os sintomas.

7. Avaliar o impacto da proposta em todos os desequilíbrios dos sistemas contidos e contenedores: prover e validar tratamentos candidatos para verificar sua viabilidade, ou seja, se podem eliminar todos os sintomas identificados no passo dois, e todos os desequilíbrios do passo 6.

8. Nomear soluções potenciais: nomear uma ou mais soluções sensatas e aceitáveis desde que exista uma, o que segundo Hitchins (2008) não é garantido.

Segundo Hitchins (2008), trabalhar com os sintomas e disfunções de uma situação do problema permite a formulação de requisitos para o tratamento da questão. Como efeito, o problema (mundo real) sugere sua própria solução (mundo ideal). 


\section{A REALIDADE DO ESTADO DO AMAZONAS}

O Estado do Amazonas possui uma população estimada de mais de três milhões de habitantes sendo dois milhões somente na capital Manaus, segundo dados do IBGE de 2006, formado por 62 municípios, abrangendo uma área de $1.570 .745 \mathrm{~km}^{2}$. Possui 25 mil quilômetros de rios navegáveis e uma frota de cerca de 70 mil barcos de médio e grande porte (FREITAS, 2009).

Existem poucas rodovias que interligam o estado do Amazonas aos seus vizinhos, sendo que a única trafegável é a que conecta Manaus à capital de Roraima, Boa Vista. A BR-319, conhecida como Transamazônica, que deveria fazer também a ligação do estado com Porto-Velho, em Rondônia, encontra-se abandonada com diversos trechos intransitáveis. Alguns municípios possuem conexão com a capital Manaus através de rodovias estaduais, como é o caso de Iranduba, Manacapuru, Itacoatiara e Novo Airão. Porém, em sua quase totalidade, o acesso aos demais municípios se dá por via fluvial ou aérea, quando possível, devido às adversidades impostas pela natureza.

[...] dependendo das condições climáticas, da seca e vazante dos rios, da situação dos aeroportos improvisados, inacabados ou em precário estado de conservação. São poucas as cidades que oferecem segurança em aeroportos e trânsito de passageiros que compensem linhas aéreas regulares. Os "barcos de recreio" ou "motores de linha", como são chamados, é que cobrem com regularidade os principais pontos do território, escoando a produção, fazendo o transporte de passageiros, cargas e informações. (BARBOSA; RAMOS, 2008, p. 19).

O Amazonas é composto por áreas espaciais diferenciadas, marcadas pelas peculiaridades constatadas na organização de seus espaços regionais com grandes extensões e acessibilidade dificultada, que se tornam os principais obstáculos para o desenvolvimento de suas estruturas produtivas. Sua 
grande extensão territorial contrasta com os baixos índices demográficos, distribuídos não uniformemente na composição do estado.

\subsection{Iniciativas em educação tecnológica no interior do Estado do Amazonas}

O Estado do Amazonas possui atualmente uma universidade federal com sede na capital Manaus e mais dezesseis núcleos no interior do Estado, uma universidade estadual presente em todos os municípios do Estado, ambas oferecendo educação de nível superior, além de contar ainda com a Secretaria de Educação para o oferecimento de ensino médio.

\subsubsection{A Universidade do Estado do Amazonas (UEA)}

A Universidade do Estado do Amazonas - UEA foi criada em 2001, através da Lei Estadual n. 2.637, de 12 de janeiro de 2001, sancionada pelo então governador Amazonino Armando Mendes, tendo como principais objetivos: promover a educação, desenvolver o conhecimento científico, particularmente sobre a Amazônia, conjuntamente com os valores éticos capazes de integrar o homem à sociedade e de aprimorar a qualidade dos recursos humanos existentes na região; ministrar cursos de grau superior, com ações especiais que objetivem a expansão do ensino e da cultura em todo o território do Estado.

\subsubsection{O Sistema Presencial Mediado por Recursos Tecnológicos (SPMRT)}

Criado em 2001 pela UEA, o Sistema Presencial Mediado por Recursos Tecnológicos - SPMRT é um método educacional cujo objetivo principal é superar as distâncias e dificuldades de acesso impostas pela geografia da região amazônica para provisão de ensino de qualidade. O SPMRT consiste na transmissão de aula a partir de um estúdio de televisão localizado na sede da universidade, de forma simultânea e ao vivo para todas as salas de 
aula geograficamente distantes, através de uma rede privativa de Internet conectada via satélite.

Os recursos humanos envolvidos no sistema são:

- Professores titulares: também conhecidos como professoresapresentadores, os professores titulares são encarregados pela elaboração e apresentação das aulas a partir do estúdio de televisão;

- Professores assistentes: acompanham os alunos de forma presencial;

- Equipe técnica de design: responsável pela transformação do material didático disponível para um padrão utilizado no meio televisivo.

Os procedimentos didáticos específicos consistem na produção de livros técnicos e elaboração de aulas, reproduzidas em textos roteirizados e slides, as quais agregam, além da descrição do conteúdo, ilustrações, fotografias e outros recursos audiovisuais.

\subsubsection{Curso de Tecnologia em Análise e Desenvolvimento de Sistemas (TADS)}

O curso TADS foi criado no ano de 2006 com o objetivo de formar tecnólogos em análise e desenvolvimento de sistemas para atuarem em pesquisa, gestão, desenvolvimento, uso e avaliação de tecnologias da informação aplicadas no mercado de computação e informática no interior do Estado do Amazonas. O curso está vinculado a uma das unidades da UEA, a Escola Superior de Tecnologia - EST.

A duração do curso é de 7 (sete) semestres, ou 42 (quarenta e dois) meses, que são equivalentes a 2040 horas no total e as aulas são ministradas cinco dias por semana, de segunda a sexta-feira, durante quatro horas por dia e, excepcionalmente, aos sábados. 
Este curso é destinado a candidatos aprovados através de prova de seleção (vestibular) realizada pela UEA, e é televisionado para 12 municípios do interior do Estado do Amazonas, onde há professores qualificados para o ensino da Computação e Informática e inseridos na cultura local.

Por ser oferecido em municípios geograficamente distantes, este curso é ministrado através do SPMRT e faz uso de todos os recursos que o referido sistema disponibiliza, o que garante a divulgação de um ensino uniforme a todos os alunos.

\subsubsection{Secretaria de Educação do Estado do Amazonas (SEDUC-AM)}

A Secretaria de Estado da Educação e Qualidade do Ensino - SEDUC-AM, além de atuar no ensino presencial regular, se aproveitou da experiência e sucesso do SPMRT implantado inicialmente na UEA, e a partir do ano de 2007 criou o Centro de Mídias, localizado na cidade de Manaus. Este centro é responsável pela transmissão das aulas das três séries do ensino médio, tendo como resultado inicial, 10 mil alunos em 42 municípios que puderam continuar seus estudos e cursar o $1^{\circ}$ ano do Ensino Médio em 2007 e em 2009 esses números de atendimento chegaram a 25.000 alunos de 62 municípios. 


\section{PROPOSTA DE PARTICIPAÇÃO EM PROJETOS DE DESENVOLVIMENTO GLOBAL DE SOFTWARE}

Municípios do Estado do Amazonas que pretendam se tornar parte integrante de projetos de desenvolvimento de software em ambientes geograficamente distribuídos devem atender a um conjunto mínimo de requisitos.

A proposta presente neste trabalho apresenta uma série de recomendações para viabilizar a preparação de municípios do Amazonas para este mercado. A seção a seguir apresenta como foram identificados os principais problemas e desafios característicos da região amazônica para ingresso no mercado de DGS. Na seção seguinte é apresentada a relação entre os principais problemas regionais e os desafios comumente encontrados durante a implementação de projetos de DGS. Por fim, são apresentadas as recomendações.

\subsection{Os principais problemas regionais}

Para identificar os principais problemas regionais quanto à geração de um mercado local que viabilize o ingresso em projetos de DGS (principais desafios), foram utilizados alguns dos métodos consensuais apresentados no capítulo 3.

O estado do Amazonas deseja desenvolver ações para viabilizar a participação de seus municípios em projetos de desenvolvimento global de software. Para definir o que precisa ser feito, é necessário identificar quais as dificuldades locais, visto que elas podem influenciar diretamente no acesso a este mercado.

Os municípios do estado do Amazonas estão dispersos geograficamente uns dos outros e também da capital Manaus, com dificuldades de acesso e 
comunicação. Atualmente, doze municípios do Amazonas estão sendo contemplados pelo curso superior de tecnologia em análise e desenvolvimento de sistemas (TADS) da UEA. Porém, após a conclusão do curso, é preciso criar alternativas para dar condições aos recém-formados para que possam desenvolver em sua localidade as atividades que aprenderam ao longo do curso.

\subsubsection{Primeira reunião: sessão de Brainstorming}

Os profissionais da UEA que atuam no curso TADS tanto na capital Manaus quanto nos municípios do interior do estado vivenciam o dia-a-dia da situação atual. Para identificar as dificuldades locais desses municípios foi realizada uma reunião com esses profissionais, entre professores titulares, professores assistentes e a coordenação do curso.

Nessa reunião foi aplicada uma sessão de brainstorming com o seguinte tema para debate: "Quais as perspectivas para os alunos dos municípios do interior do estado do Amazonas após sua graduação em cursos de tecnologia?".

Como resultado, a seguinte lista de tópicos foi gerada:

- Possibilidade de qualificação em pesquisas, através de cursos de mestrado, doutorado e pós-doutorado;

- Migração para outras localidades, gerando êxodo municipal;

- Desativação dos cursos for falta de continuidade dos investimentos;

- Geração de um pólo de produção de software utilizando mão-de-obra local.

A figura 12 apresenta o mapa mental $l^{7}$ criado para apoiar os participantes na elaboração das idéias, com objetivo de melhorar a associação e comunicação das mesmas.

\footnotetext{
${ }^{7}$ Representações gráficas utilizadas para escrever idéias e conceitos, criada pelo inglês Tony Buzan.
} 


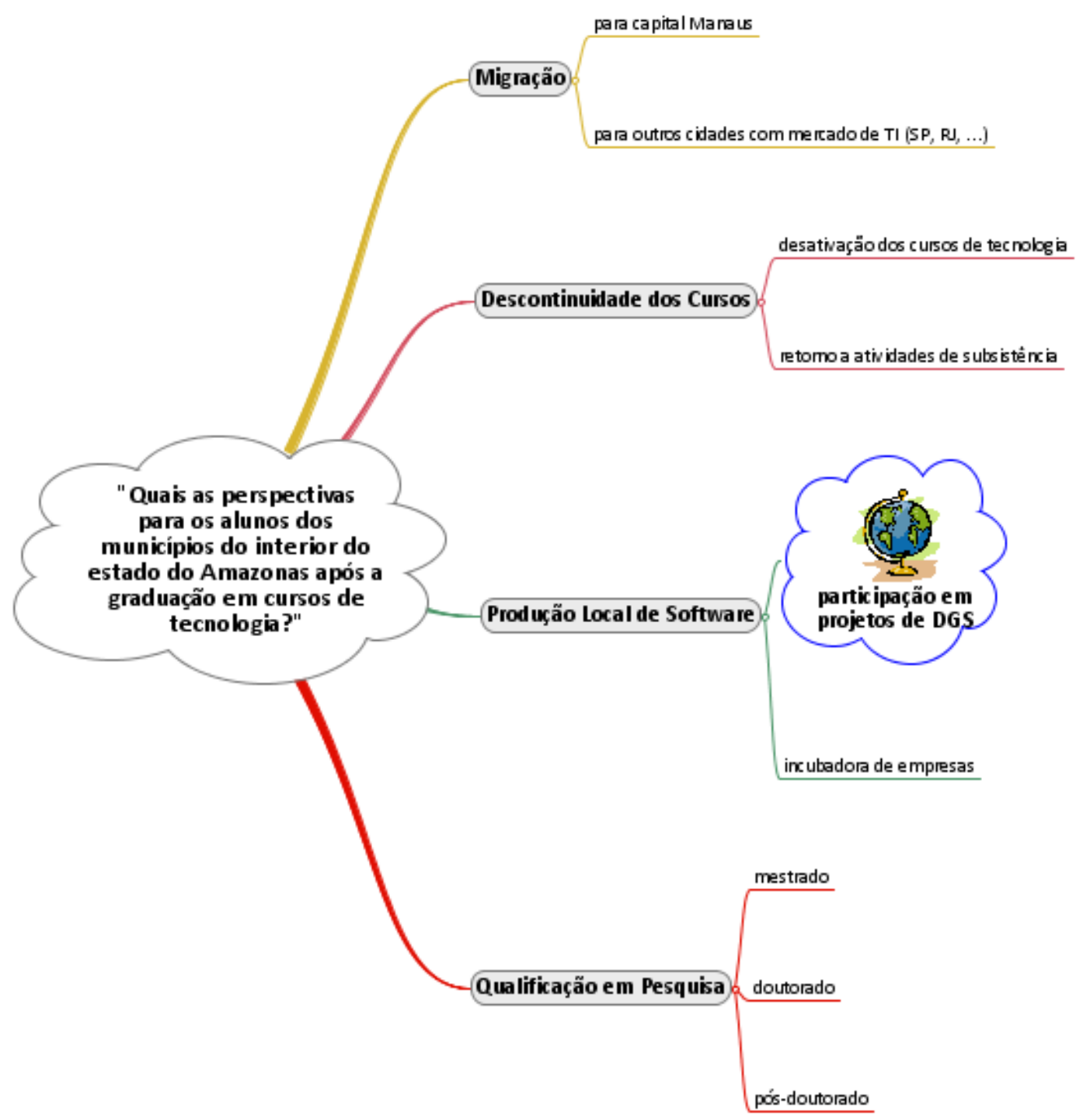

Figura 12 - Mapa mental da sessão de brainstorming

Caso não existam perspectivas locais para os recém-formados, uma possibilidade latente é sua migração para outras cidades que ofereçam oportunidades de empregabilidade, como para a capital Manaus ou até mesmo para cidades de outras regiões do país, como São Paulo, Rio de Janeiro, Porto Alegre, Recife, entre outras.

Ao levar ensino tecnológico de nível superior para os municípios do interior do Estado do Amazonas, busca-se alavancar o desenvolvimento local através da qualificação técnica da sua comunidade. Porém, sem alternativas de continuidade, é bem provável que estes cursos percam o fator 
motivacional, tanto por parte das instituições de ensino quanto dos próprios alunos. Por isso, durante a reunião foi cogitada a possibilidade de descontinuidade dos cursos após alguns anos, levando os recém-formados que não têm condições de migrar para outras cidades a retornar às suas atividades locais, muitas vezes voltadas para cultura de subsistência.

Um cenário mais promissor citado durante a reunião seria a criação de um plano de continuidade da formação desses alunos com foco em qualificação em pesquisa científica, através de cursos de mestrado, doutorado e pósdoutorado, em parceria com instituições de outras cidades.

Porém, dentre os tópicos gerados destaca-se a produção local de software, com a possibilidade de geração de um mercado local de desenvolvimento a partir da qualificação dos recém-formados nos cursos de tecnologia dos municípios. Neste item, foi discutida em reunião a possibilidade de preparação dos profissionais para atuarem em projetos de desenvolvimento global de software, tornando-os aptos a participarem de etapas do ciclo de vida, como por exemplo, na fase de construção ou testes. Esta opção está destacada no diagrama no item Produção Local de Software - Participação em Projetos de DGS.

Por ser uma opção atrativa para continuidade do desenvolvimento dos municípios atendidos pelos cursos da UEA, essa opção foi selecionada pelos participantes para um maior aprofundamento do estudo.

\subsubsection{Segunda reunião: sessão de Técnica de Grupo Nominal (TGN)}

Foi realizada uma segunda reunião com os mesmos participantes da sessão de brainstorming, e desta vez foi aplicada a Técnica de Grupo Nominal, com o objetivo de promover um senso comum sobre os principais desafios para viabilizar a participação do estado do Amazonas em projetos de DGS.

O resultado da segunda reunião está representado no mapa mental da figura 13: 


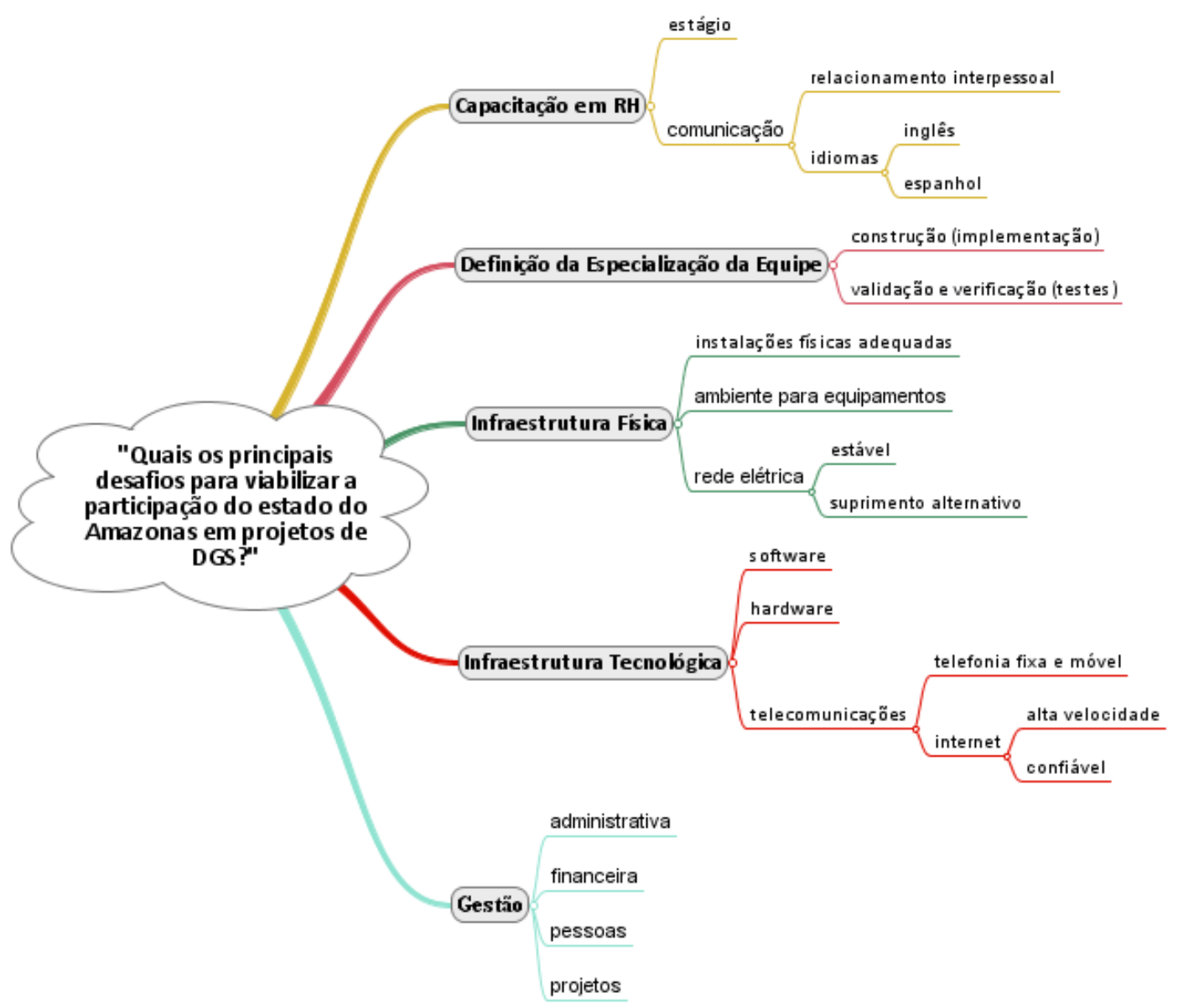

Figura 13 - Mapa mental da sessão de TGN

\subsubsection{Consolidação dos principais problemas regionais}

Ao consolidar os dados coletados na segunda reunião, o resultado pode ser sumarizado na seguinte lista:

- Capacitação dos recursos humanos: para atender ao perfil necessário para atuar em mercados globalizados;

- Provisão de Infraestrutura física: através da disponibilização de ambientes adequados para trabalho e instalação de equipamentos;

- Provisão de Infraestrutura tecnológica: definição dos produtos de software e hardware necessários, além da provisão de recursos de telecomunicações. 


\subsection{A proposta sob uma visão empreendedora}

Define-se o empreendedor como aquele que irá criar meios para alcançar o sucesso em uma dada oportunidade. Souza e Guimarães (2005) citam a definição sobre empreendedorismo como sendo uma "destruição criativa", a percepção e a exploração de novas oportunidades, no âmbito de negócios, utilizando recursos disponíveis de maneira inovadora. Segundo o autor, "o empreendedor é aquele que destrói a ordem econômica existente através da introdução de novos produtos e serviços, pela criação de novas formas de organização, ou pela exploração de novos recursos e materiais.".

Para dar forma ao seu novo empreendimento, a inclusão de municípios do Amazonas em projetos de DGS, uma alternativa para o empreendedor é formalizar a criação de uma empresa. Nesta proposta, a empresa apresentada é formada por dois componentes que determinam seu potencial para ingresso no mercado global de desenvolvimento de software: suas competências e suas estratégias de negócio (Figura 14).

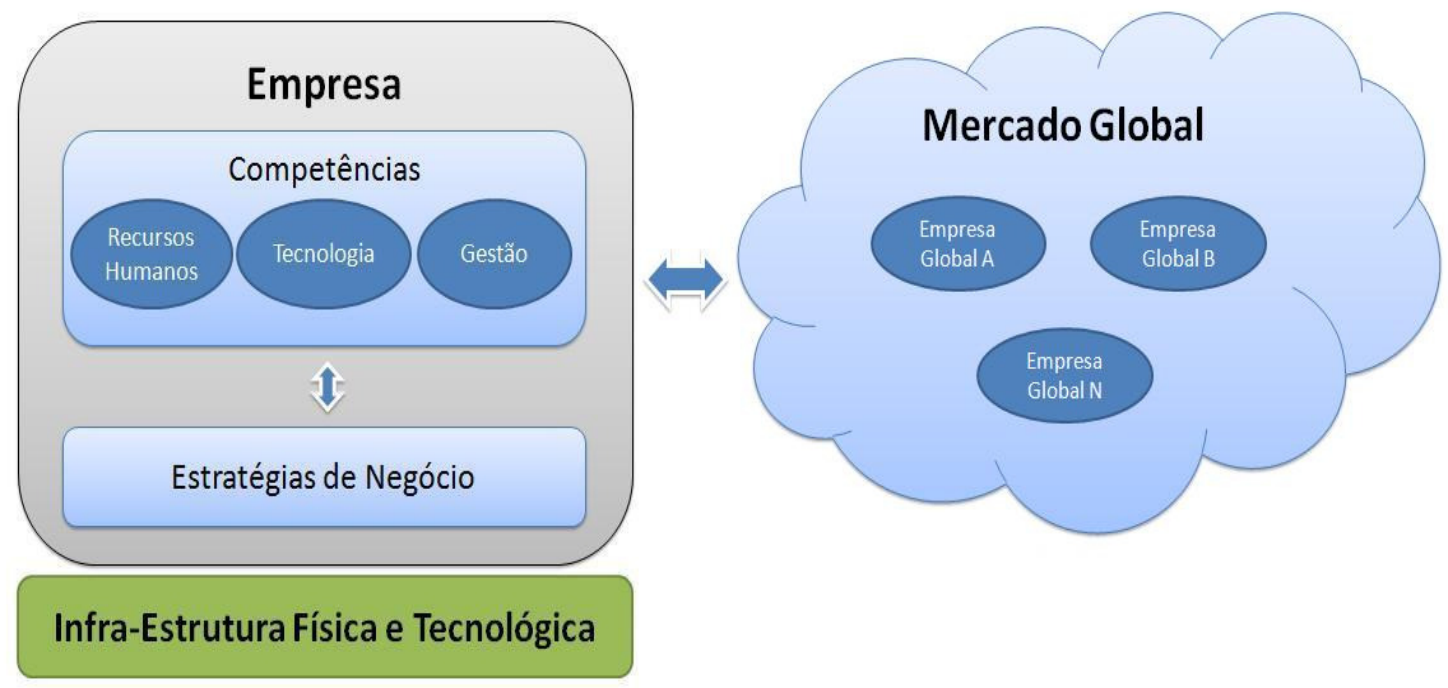

Figura 14 - A proposta sob uma visão empreendedora

As competências organizacionais são aquelas que a empresa utiliza no desenvolvimento de suas atividades. Ela pode já possuí-las ou deverá desenvolvê-las. A estratégia da empresa pode ser definida de acordo com as competências que a empresa possui, mas sofre forte influência das 
condições determinadas pelo mercado global. A estratégia também pode ser responsável pela alteração das competências que a empresa possui, ou aponta para o desenvolvimento de novas competências necessárias para adequação da empresa às demandas do mercado global.

- Recursos humanos

Pessoas que compõem a empresa. Existe uma relação forte de influência mútua entre os recursos humanos e a estratégia da empresa. Para atender à estratégia da empresa, as pessoas precisam alcançar um alto nível de qualificação e estar preparadas para atender às demandas do mercado global.

É importante definir corretamente o perfil do profissional que a empresa estará incorporando ao seu quadro funcional, qual será o programa de capacitação que será oferecido, em que idiomas serão treinados para melhorar a comunicação com outros grupos, etc.

- Tecnologia

Serviços, produtos e processo que a empresa irá oferecer ao mercado global. Neste item estão incluídas ferramentas para facilitar a comunicação, estratégia para implementação de intercâmbio entre membros das equipes dispersas, além da definição e institucionalização de um processo de desenvolvimento.

- Gestão

Responsável pela orquestração de todas as atividades e processos desenvolvidos pela empresa. Esta competência deverá ser capaz de planejar e executar a estratégia necessária para que a empresa possa ser atrativa ao mercado global. Além disso, deverá prover mecanismos para facilitar a coordenação e controle dos projetos, como disponibilização e compartilhamento de informações sobre os mesmos, distribuição correta das responsabilidades. 
Na área de gestão também estão incluídas as áreas responsáveis pelo apoio ao negócio: gestão tecnológica, estratégica, administrativa e financeira, e outras que se fizerem necessárias.

É importante observar que na base, como alicerce da empresa, encontra-se a infraestrutura, tanto física quanto tecnológica, responsável por viabilizar a execução da estratégia de negócio da empresa e, conseqüentemente, pelo seu desenvolvimento.

\subsection{As recomendações}

Ao considerar que nos municípios do estado do Amazonas não existem iniciativas para participação em projetos de desenvolvimento global de software, ou sequer pólos de desenvolvimento de software, exceto na capital Manaus, foi definido um conjunto de recomendações para empreendedores que desejam alavancar esta oportunidade. Tais recomendações configuramse como sugestões que têm por finalidade mitigar tanto os principais problemas vivenciados e apontados pela literatura sobre DGS quanto os problemas peculiares da região que podem influenciar na decisão de adesão ao modelo globalmente distribuído de desenvolvimento de software.

Ao analisar os problemas regionais citados na seção 5.1.3, identificou-se que é possível estabelecer a seguinte relação entre os problemas regionais e os desafios do DGS, conforme a figura 15:

- O problema regional Recursos Humanos pode ser relacionado com os desafios do DGS Pessoas, Gestão e Comunicação;

- O problema regional Infraestrutura, tanto física quanto tecnológica, pode ser relacionado com os desafios do DGS Tecnologia e Processos.

Dessa forma, foram definidas as recomendações baseadas em duas categorias: recursos humanos, infraestrutura física e tecnológica. Estas recomendações serão apresentadas nas seções a seguir. 


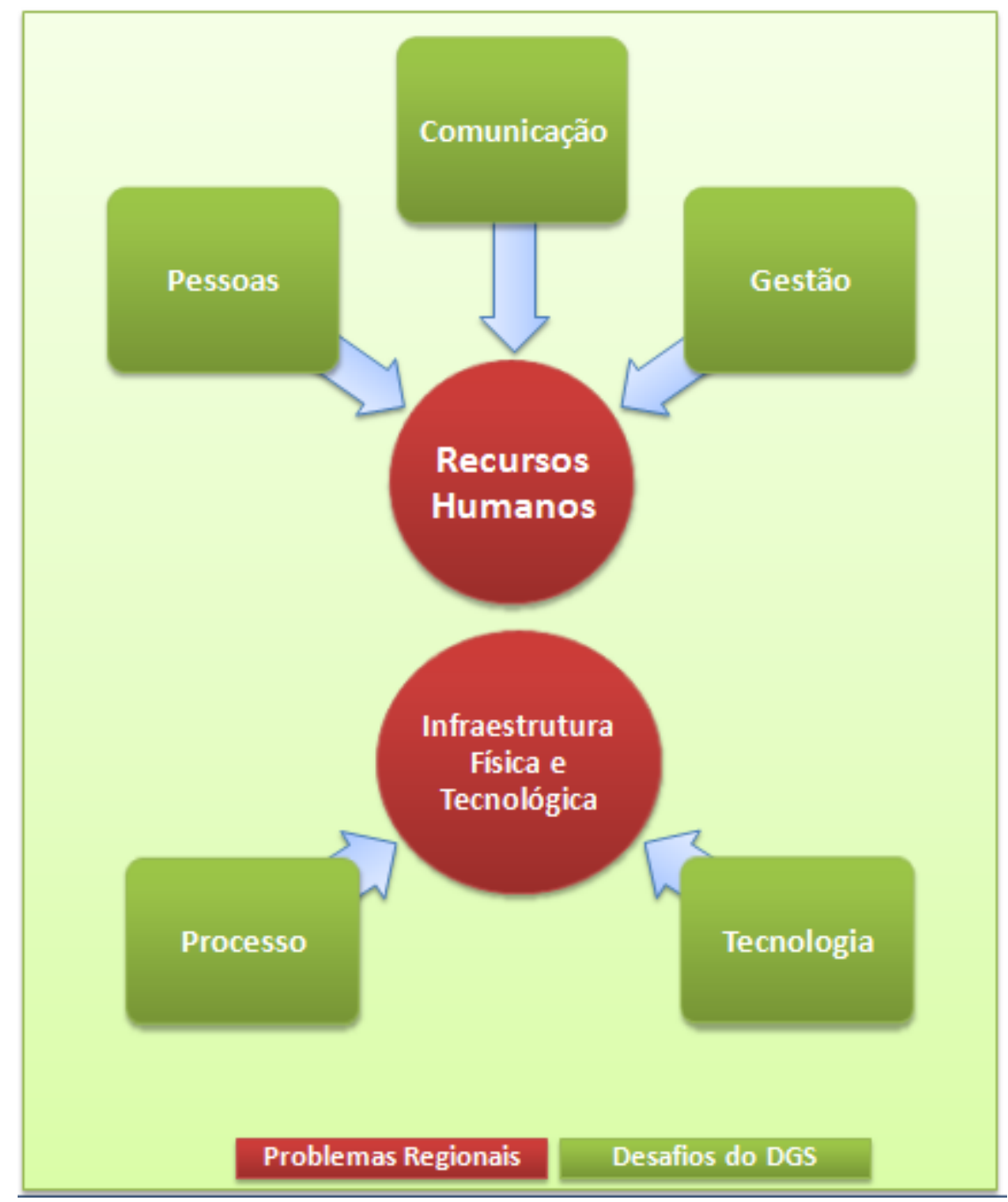

Figura 15 - Relação entre desafios do DGS e problemas regionais

\subsubsection{Recomendações relacionadas aos recursos humanos}

Para ingressar no mercado de DGS, o corpo técnico precisa ter domínio deste modelo de negócio, porque a empresa está interessada neste segmento de mercado, quais os principais desafios e as soluções já consolidadas quanto à adoção do DGS.

Para preparar este profissional, as seguintes ações são necessárias:

RH1. Treinamento em DGS: considera a necessidade de apresentar dados essenciais para tornar o conhecimento sobre o desenvolvimento distribuído 
de software de domínio do profissional que irá atuar neste mercado. O objetivo principal neste treinamento é mostrar para o profissional seu papel, sua importância dentro do projeto de desenvolvimento distribuído de software e como ele poderá contribuir indiretamente para alavancar a economia local.

RH2. Treinamento nas metas organizacionais: está relacionado aos serviços oferecidos pela empresa ao mercado global, pois o profissional necessita ter a visão da missão da empresa e qual o papel da organização dentro deste segmento, quais suas expectativas. Por exemplo, a organização deseja atuar no segmente de validação de software. Dessa forma, realizar workshops com os profissionais da empresa, apresentando quais os objetivos estratégicos da empresa, tornando-os transparentes para todos, de forma até a contribuir para motivação de todos os envolvidos.

$\mathrm{RH}$ 3. Treinamento em idiomas: para atuar no mercado global, certamente é necessário dominar um segundo idioma. Dessa forma, é necessário planejar e executar treinamentos específicos para o idioma do país com o qual a empresa irá interagir. $\mathrm{O}$ inglês em especial é mandatório no segmento de desenvolvimento de software, portanto, um bom ponto de partida.

RH4. Planejamento de estudos de caso: para obter sucesso no mercado de desenvolvimento de software é necessário mostrar suas competências. Para que elas apareçam é necessário gerar oportunidades e adquirir experiência. Neste caso, a recomendação é envolver os profissionais em projetos simulados, estudos de caso e programas de estágio.

\subsubsection{Recomendações relacionadas à infraestrutura física e tecnológica}

A infraestrutura necessária para implantar o DGS não está presente atualmente no Estado do Amazonas, visto que a totalidade de suas cidades, exceto a capital Manaus, não possui tecnologia em telecomunicações ou mesmo um ambiento físico adequado para a execução das tarefas. 
Como relatado nas seções anteriores, as infraestruturas física e tecnológica em projetos de DGS são essenciais para minimizar os impactos decorrentes da dispersão geográfica e temporal.

Para mudar este cenário, são apresentadas as seguintes recomendações:

INFRA1. Melhoria urgente no sistema de transporte local, visto que muitos municípios possuem acesso limitado, sem aeroportos adequados e sem vias de acesso terrestre.

INFRA2. Provisão de energia elétrica suplementar, para evitar indisponibilidade de recursos energéticos. Além disso, a rede elétrica deve ser estável, para evitar danos e perdas de equipamentos e até mesmo dados.

INFRA3. Validação de requisitos de software, tais como verificação de compatibilidade de versões entre as equipes, questões relacionadas a licença de software, aquisição de software de sistemas operacionais, ferramentas CASE, IDES, ferramentas para gerenciamento de projetos.

INFRA4. Validação de requisitos de hardware, envolvendo especificação de hardware, servidores, dispositivos de redes e recursos para ambientes distribuídos.

INFRA5. Validação de requisitos em telecomunicações, com provisão de recursos para comunicação remota entre equipes de projeto, conexão de internet confiável e redes de alta performance.

INFRA6. Oferecimento de ambiente físico de trabalho favorável, atrativo e que permita ao profissional se sentir confortável, com móveis ergonomicamente válidos e ambiente aclimatizado. 


\section{CONSIDERAÇÕES FINAIS}

Este trabalho teve como objetivo principal descrever um conjunto de recomendações para auxiliar o ingresso do Estado do Amazonas em projetos com características distribuídas em escala global. Este capítulo apresenta as considerações finais sobre o trabalho, aponta as principais contribuições dadas e propõe alguns trabalhos futuros.

\subsection{Avaliação da proposta}

A proposta apresentada neste trabalho busca cobrir os aspectos técnicos envolvidos no processo de desenvolvimento de software. É importante notar que questões periféricas, mas não menos importantes, como legislação, estratégias de mercado, modelos de negócios, entre outras, não foram abordadas. $\mathrm{O}$ objetivo foi centralizar as ações nos aspectos de engenharia relacionados, como infraestrutura e os fatores humanos envolvidos na avaliação de todo o cenário.

Ao associar os problemas regionais com os principais desafios do DGS, busca-se utilizar o que a academia e indústria oferecem de experiência e como elas contribuem para minimizar riscos na definição das recomendações.

\subsection{Contribuições}

Este trabalho permitiu explorar duas áreas do conhecimento em engenharia de software: o desenvolvimento global de software e a engenharia de requisitos. No DGS, foi possível realizar uma profunda revisão dos conceitos e apresentar estudos empíricos para verificar como estes conceitos estão presentes no dia-a-dia da indústria e evidenciar os desafios que esta forma de desenvolvimento traz consigo, bem como as ações que tem sido tomadas no mundo real para mitigá-los. 
$\mathrm{Na}$ área de engenharia de requisitos, o trabalho ofereceu uma visão breve, porém muito objetiva do processo e como é possível obter um consenso entre os envolvidos no projeto sobre o que deve ser feito e o que deve ser priorizado. Os métodos consensuais apresentam um olhar alternativo para a principal atividade do processo, o levantamento de requisitos sob a abordagem da engenharia de sistemas.

Porém, a maior contribuição está na possibilidade de colocar em evidência uma reflexão tão importante sobre o futuro da região amazônica. As comunidades dos municípios mais carentes do Estado do Amazonas, devido a toda a limitação de acesso a recursos básicos para o desenvolvimento de suas localidades, se sentem realizadas ao receber ensino de nível superior de qualidade onde elas residem, oferecendo a oportunidade de permanecerem onde querem estar e com novas perspectivas. Todavia, caso simplesmente creia que esta ação é suficiente para alavancar o progresso dessas cidades, o Estado do Amazonas estará apenas retardando o processo de decadência total dos municípios.

Este trabalho oferece a oportunidade de debater alternativas sustentáveis para fomentar o desenvolvimento regional sem agredir a natureza, permitindo a inclusão digital de várias comunidades, e oferecendo um novo horizonte como perspectiva positiva, aliando capacitação tecnológica, resgatando a auto-estima de um povo tão sofrido e isolado como os dessas comunidades e principalmente trazendo à discussão um possível caminho para trilhar rumo ao progresso.

\subsection{Trabalhos futuros}

Este trabalho não apresenta validação das recomendações propostas, pois seu objetivo é elaborar uma proposta de inclusão do Amazonas em projetos de DGS.

Os próximos passos incluem a realização de estudos empíricos para colocar a prova as recomendações propostas, através da estruturação de projetos que incluam os municípios cobertos pelos cursos do TADS da UEA e 
unidades da capital Manaus, além de buscar o envolvimento da comunidade internacional, para assim potencializar a diversidade cultural dos atores envolvidos.

Outras atividades podem incluir uma análise mais profunda dos fatores culturais intrínsecos da região amazônica e sua influência em equipes de projetos de desenvolvimento distribuído de software. 


\section{REFERÊNCIAS}

A.T. KEARNEY. The 2009 A.T. Kearney Global Services Location Index The Shifting Geography of Offshoring. Disponível em: http://www.atkearney.com/ index.php/Publications/global-services-locationindex-gsli-2009-report.html. Acesso em: 27/08/09.

ABBATTISTA, F. et al. Incorporating Social Software Into Distributed Agile Development Environment. $23^{\text {rd }}$ IEEE/ACM International Conference on Automated Software Engineering, ASE. p.46-51, 2008.

AL-ANI, B.; REDMILES, D. In Strangers We Trust? Findings of an Empirical Study of Distributed Teams. IEEE International Conference on Global Software Engineering - ICGSE. p. 121-130, 2009.

ASPRAY, W.; MAYADAS, F.; VARDI, M. Y. Report: Globalization and Offshoring of Software - A report of the ACM Job Migration Task Force. ACM - Association for Computer Machinery, 2000. Disponível em: http://www.acm.org/globalizationreport/. Acesso em: 04/08/09.

AUDY, J.; PRIKLADNICKI, R. Desenvolvimento Distribuído de Software desenvolvimento de software com equipes distribuídas. $1^{\circ}$ ed. Rio de Janeiro. Elsevier, 2008. 211p.

BARBOSA, W. A.; RAMOS, J. A. G. MANAUS: UEA Proformar e a Educação no Amazonas. Editora Valer. 2008.

BOEHM, B. A Spiral Modelo f Software Development and Enhancement. IEEE Computer, Vol. 21 Issue 5, Maio. p. 61-72, 1988.

BORCHERS, G. The Software Engineering Impacts of Cultural Factors on Multi-Cultural Software Development Teams. Proceedings of the $25^{\text {th }}$ International Conference on Software Engineering, ICSE. p.540-545, 2003. 
BROCKMANN, P. S.; THAUMULLER, T. Cultural Aspects of Global Requirements Engineering - An Empirical Chinese-German Case Study. IEEE International Conference on Global Software Engineering - ICGSE. p. 353-357, 2009.

CAETANO, R. Mercado de terceirização brasileiro crescerá $10 \%$ em 2009. ComputerWorld Online. Disponível em: http://computerworld.uol.com.br/ negocios/2009/07/15/mercado-deterceirizacao-brasileiro-crescera-10-em-2009/. Acesso em: 26/08/09.

CARMEL, E. Thirteen Assertions for Globally Dispersed Software Development Research. Proceedings of the $30^{\text {th }}$ Hawaii Conference on System Sciences, HICSS 30. Volume 3, p. 445, 1997.

CARMEL, E.; ARGWAL, R. Tactical Approaches for Alleviating Distance in Global Software Development. IEEE Software, Março/Abril, p. 22-29, 2001.

CARMEL, E.; DUBINSKY, Y.; ESPINOSA, A. Follow the Sun Software Development: New Perspectives, Conceptual Foundation, and Exploratory Field Study. Proceedings of the $42^{\text {nd }}$ Hawail International Conference on System Sciences, HICSS 42. p. 1-9, 2009.

CASEY, V. Leveraging or Exploiting Cultural Difference? IEEE International Conference on Global Software Engineering - ICGSE. p. 8-17, 2009.

CATALDO, M. et al. CAMEL: A Tool for Collaborative Distributed Software Design. IEEE International Conference on Global Software Engineering - ICGSE. p. 83-92, 2009.

CHECKLAND, P. Soft Systems Methodology: A Thirty Year Retrospective. Systems and Research and Behavioral Science, Vol. 17. p. S11-S58, 2000. 
CHECKLAND, P.; POULTER, J. Learning for Action - A Short Definition Account of Soft Systems Methodology and its Use for Practitioners, Teachers and Students. Chichester: Wiley. 2006. 200p.

CMMI. CMMI for Development, version 1.2 - Improving Processes for Better Products. Report CMU/SEI-2006-TR-008. Carnegie-Melon Software Institute, $2006 . \quad$ Disponível em: http://www.sei.cmu.edu/library/abstracts/reports/06tr008.cfm. Acesso em: 13/05/2010.

CONCHÚlR, E. O. et al. Global Software Development: Where Are The Benefits?. Communications of the ACM, Agosto, Vol. 52. Nro.8. p. 127-131, 2009.

DAMIAN, D.; MOITRA, D. Global Software Development: How Far Have We Come?. IEEE Software. Setembro/Outubro. p. 17-19, 2006.

DAMIAN, D. Stakeholders in Global Requirements Engineering: Lessons Learned from Practice. IEEE Software, Março/Abril, p. 21-27, 2007.

DAMIAN, D. ZOWGHI, D. Requirements Engineering Challenges in Multisite Software Development Organizations. Requirements Engineering Journal, Vol. 8. p. 149-160, 2003.

FREITAS, M. Iniciativas e Perspectivas dos Programas de PósGraduação Stricto Sensu em Eduação Tecnológica no Estado do Amazonas. Revista T\&C Amazônia, Amazonas, Ano VII. Número 6, p. 5461. 2009.

FRYER, K.; GOTHE, M. Global Software Development and Delivery: Trends and Challenges. Disponível em: http://www.ibm.com/developerworks/rational/ library/edge/08/ jan08/fryer_gothe/index.html. Acesso em: 10/10/2009.

GIL, A. C. R. Brazil: An IT Giant Goes Global. XXI Fórum Nacional 2009 $\mathrm{Na}$ Crise Global, o Novo Papel Mundial dos BRICs e as Oportunidades do 
Brasil. Disponível em: http://www.forumnacional.org.br/sec.php?s=490\&i=pt Acesso em: 30/09/09.

GOTTESDEINER, E. Requirements by Collaboration. Addison-Wesley, 2002.

HALVEY, J. K.; MELBY, B. M. Information Technology Outsourcing Transactions - Process, Strategies and Contracts. 2o ed. New Jersey. Wiley, 2005. 648p.

HERBSLEB, J. D.; MOITRA, D. Global Software Development. IEEE Software, Março/Abril, p. 16-20, 2001.

HERBSLEB, J. D. Global Software Engineering: The Future of Sociotechnical Coordination. International Conference on Software Engineering Future of Software Engineering - p. 188-198, 2007.

HERBSLEB, J. D.; GRINTER, R. E. Architectures, Coordination, and Distance: Conway's Law and Beyond. IEEE Software, Setembro/Outubro, p. 63-70, 1999.

HICKEY, A. M.; DAVIS, A. M. Requirements Elicitation and Elicitation Technique Selection: A Model for Two Knowledge-Intensive Software Development Processes. Proceedings of the $36^{\text {th }}$ Hawaii Conference on System Sciences, HICSS 36. Volume 3, p. 96a, 2003.

HITCHINS, D. K. Systems Engineering: A $21^{\text {st }}$ Century Systems Methodology. Chichester: John Wiley \& Sons, 2008. 528p.

HOLTZBLATT, K.; BEYER, H. R. Requirements Gathering: The Human Factor. Communications of the ACM, Maio, Vol. 38. Nro.5. p. 31-32, 1995.

IDC. Tendências e Projeções de Infraestrutura de TI no Brasil. Disponível em: http://www.scherm.com.br/arquivos/documentos/idc2.pdf. Acesso em: 30/09/09. 
IEEE, IEEE Standard 610.12 - IEEE Standard Glossary of Software Engineering Terminology. New York: IEEE Computer Society, 1990. 84p.

IEEE Computer Society. SWEBOK - Guide to the Software Engineering Body of Knowledge. California: Angela Burgess, 2004. Disponível em http://www.swebok.org.

KAROLAK, D. W. Global Software Development: Managing Virtual Teams and Environment. IEEE Computer Society Press, 1998. 174p.

KATAMA, M. I.; TAMAI, T. How Does Requirements Quality Relate to Project Success or Failure? Proceedings of the $15^{\text {th }}$ IEEE International Requirements Engineering Conference - p. 69-78, 2007.

KOMMEREN, R.; PARVIAINEN, P. Philips Experiences in Global Distributed Software Development. Empirical Software Engineering, Springer Netherlands. Vol. 12. Nro. 6. p. 647-660, 2007.

KOTONYA, G.; SOMMERVILLE, I. Requirements Engineering: Processes and Techniques. Londres: Wiley, 1998. 294p.

LANUBILE, F. et al. Collaboration Tools for Global Software Engineering. IEEE Software, Março/Abril, p. 52-55, 2010.

LEITE, J. C. S. P., Livro Vivo: Engenharia de Requisitos. Disponível em: http://livrodeengenhariaderequisitos.blogspot.com/. Acesso em: 10/10/09.

LUTZ, B. Linguistic Challenges in Global Software Development: Lessons Learned in an International SW Development Division. IEEE International Conference on Global Software Engineering - ICGSE. p. 249253, 2009.

MACGREGOR, E.; HSIEH, Y. KRUTCHEN, P. The Impact of Intercultural Factors on Global Software Development. Canadian Conference on Electrical and Computer Engineering, p. 920-926, 2005. 
MULLICK, N. et al. Siemens Global Studio Project: Experiences Adopting and Integrated GSD Infrastructure. IEEE International Conference on Global Software Engineering - ICGSE. p. 203-212, 2006.

NASSCOM. Perspectives 2020: Transform Business, Transform India. Disponível em: http://www.nasscom.org/nasscom/templates/LandingNS.aspx?id=57 764 . Acesso em: 06/10/09.

NIINIMAKI, T.; LASSENIUS, C. Experiences of Instant Messaging in Global Software Development Projects: A Multiple Case Study. IEEE International Conference on Global Software Engineering - ICGSE. p. 55-64, 2008.

NUSEIBEH, B.; EASTERBROOK, S. Requirements Engineering: A Roadmap. Proceedings of the Conference on the Future of Software Engineering - p. 35-46, 2000.

PERSSON, J. S.; MATHIASSEN, L. A Process for Managing Risks in Distributed Teams. IEEE Software, Janeiro/Fevereiro, p. 20-29, 2010.

PILATTI, L.; AUDY, J. L. N.; PRIKLADNICKI, R. Software Configuration Management over a Global Software Development Environment: Lessons Learned from a Case Study. Proceedings of the 2006 International Workshop on Global Software Development for the Practitioner. p. 45-50, 2006.

SCHNIEDERJANS, M. J. et al. Outsourcing and Insourcing in an International Context. New York: M.E. Sharpe, 2005. 208p.

SIQUEIRA, F. L. O Desenvolvimento Distribuído de Software: Características e Recomendações para a Gerência de Projetos. 2005. 152p. Dissertação (Mestrado em Engenharia Elétrica) - Escola Politécnica, Universidade de São Paulo, São Paulo, 2005. 
SIMONETTE, M. J. Engenharia de Sistemas em Sistemas Sociotécnicos. 2010. 115p. Dissertação (Mestrado em Engenharia Elétrica) - Escola Politécnica, Universidade de São Paulo, 2010.

SOMMERVILLE, I.; SAWYER, P. Viewpoints: Principles, Problems and a Practical Approach to Requirements Engineering. Annals of Software Engineering.Springer Netherlands, Vol. 3. Nro. 1. p. 101-130. Janeiro, 1997.

SOUZA, E. C. L. de; GUIMARÃES, T. de A. Empreendedorismo além do plano de negócio. $1^{\circ}$ ed. São Paulo: Atlas, 2005. 564p.

ZAVE, P. Classification Efforts in Requirements Engineering. ACM Computing Surveys. Vol. 29. Nro. 4. p. 315-321, 1997.

ZOWGHI, D.; PARYANI, S. Teaching Requirements Engineering Through Role Playing: Lessons Learnt. Proceedings of the $11^{\text {th }}$ IEEE International Requirements Engineering Conference - p. 233, 2003. 